\title{
Fuzzy logic based automation and control simulation of Sulfuric acid manufacturing process: A case study
}

\author{
Dinesh Singh Rana \\ Department of Instrumentation, Kurukshetra University, Kurukshetra
}

\begin{abstract}
Control of Chemical Plant is important because it further comprises of small plants ranging from water control up to the chemical composition control. Most of the chemical processes are non linear and non stationary. Also the process dynamics of these processes is not well understood due to some unknown disturbances. So fuzzy logic control is best suited for such types of processes where process dynamics is complex. In present paper, a Fuzzy logic system has been purposed that is particularly suited for Sulfuric acid plant. The system design starts from identification of inputs, Outputs and choosing the membership function for each condition from normal operation up to emergency operation of sulfuric plant. A complete automation and control of sulfuric acid production process has been implemented which show consistent results.
\end{abstract}

Keywords: - Fuzzification, Inference Engine, defuzzification, process dynamics, membership functions

\section{Introduction}

Most of chemical reaction processes are nonlinear in nature. Moreover its modeling is also complicated. In chemical industry, the processes are in general complex, with delays, non-linearity; it is not always possible to control them with classical regulators [1]. The major disadvantage in fuzzy control is lacking analytical design technique i.e. determination of parameters of Membership functions [2-3]. Basic knowledge of pure physics and chemistry is needed with advanced engineering for the development of Instrumentation system to chemical process control. Conventional and advanced controllers (like PID \& MRAC respectively) need most accurate modeling; in addition simulation has also some defects in virtual implementation and testing. Fuzzy controllers have a non-linear behavior that makes them a useful tool for the chemistry industry [4].

The application of the Fuzzy Set Theory to a wide range of control applications has made possible the establishment of intelligent control in these areas [5]. A relationship is to be developed between the inputs and outputs with the help of the fuzzy logic controller [6]. Sulfuric Acid production is also one of the nonlinear and in addition exothermic one. Here two parameters, concentration and temperature plays vital role and shows nonlinear behavior while producing sulfuric acid. For accurate and safe operation one must have a very good mathematical model of both plants as well process. It is difficult to get good control and accuracy due to less reliability of mathematical model or errors in the model. So instead of conventional or advanced controller which totally depends on the mathematical model, fuzzy logic control strategy has been selected as an option. This scheme of control will evaluate certainty within uncertainty and handling the parameters within range to control the entire process continuously though fluctuations occurs [7-8]. Fuzzy control provides effective solutions for nonlinear and partially unknown processes, mainly because of its ability to combine information from different sources [9]. The fuzzy knowledge base consists of a set of physically interpretable if- then rules providing physical insight into the process [10]. Therefore the process industries require more reliable, accurate, robust, efficient and flexible control systems for the operation of process plant.

\section{Process dynamics: Production of sulfur dioxide}

The flow diagram of sulfuric acid manufacturing process is shown in figure 1. Solid Sulfur is melted by steam coils at $140^{\circ} \mathrm{C}$ in brick lined tanks. The molten sulfur is filtered to remove any impurities (usually iron or organic compounds). The molten sulfur is pumped to the burner where it is burnt in an excess of dry air. The gas exiting the burner is maintained at $8-9 \% \mathrm{v} / \mathrm{v}$ sulfur dioxide and approximately $830^{\circ} \mathrm{C}$ due to the heat produced by the exothermic reaction [3]. This reaction is described by the equation[3]:

$$
\mathrm{S}+\mathrm{O}_{2} \rightarrow \mathrm{SO}_{2} \quad \text { (1) } \quad \Delta H=-300 \mathrm{~kJ} \text { mol-1 }
$$

The sulfur dioxide/air gas mixture is then passed through the hot gas filter situated besides the air burner, where any ash contamination is removed. The sulfur dioxide is converted to sulfur trioxide by reacting with oxygen over a catalyst. This reaction is described by the equation:

$$
\mathrm{SO}_{2}+\frac{1}{2} \mathrm{O}_{2} \rightarrow \mathrm{SO}_{3} \quad \text { (2) } \quad \Delta H=-100 \mathrm{~kJ} \text { mol-1 }
$$

This reaction occurs in the converter in which a four-stage reaction vessel, with each stage consisting of a solid catalyst bed through which the gas is passed. The catalyst used is vanadium pent oxide $\left(\mathrm{V}_{2} \mathrm{O}_{5}\right)$ and potassium sulphate dispersed on a silica base; this forms a porous support, giving a large surface area for reaction. It is believed that the $\mathrm{V}_{2} \mathrm{O}_{5}$ increases the rate of the overall chemical reaction by oxidizing the $\mathrm{SO}_{2}$ to $\mathrm{SO}_{3}$ and 
Fuzzy logic based automation and control simulation of Sulfuric acid manufacturing process: A case

being re-oxidized itself by the oxygen in the gas stream. This reaction is exothermic and its equilibrium constant decreases with increasing temperature. Figure 1 shows the percentage conversion of $\mathrm{SO}_{2}$ to $\mathrm{SO}_{3}$ that would be reached at an $\mathrm{SO}_{2}$ concentration of $8 \% \mathrm{v} / \mathrm{v}$ and a range of gas temperatures. However, the reaction rate is also temperature dependent, so that if the temperature becomes too low the equilibrium point will not be reached. In practice, the gas temperature must be maintained between $400-500^{\circ} \mathrm{C}$ to maintain a high reaction rate and also high conversion equilibrium [3]. As the reaction is exothermic, heat is generated across each of the catalyst beds. This heat must be removed between each stage to maintain the optimum reaction temperature into the following stage. The greatest degree of cooling is required between the first and second stages. Cooling after the second and third stages is by injection of dried air. The gas is passed to the absorption tower, a packed tower where $\mathrm{SO}_{3}$ is absorbed into a counter-current flow of $98-99 \%$ sulfuric acid. The overall reaction can be described by the following equation, where sulfur trioxide reacts with the free water to produce sulfuric acid:

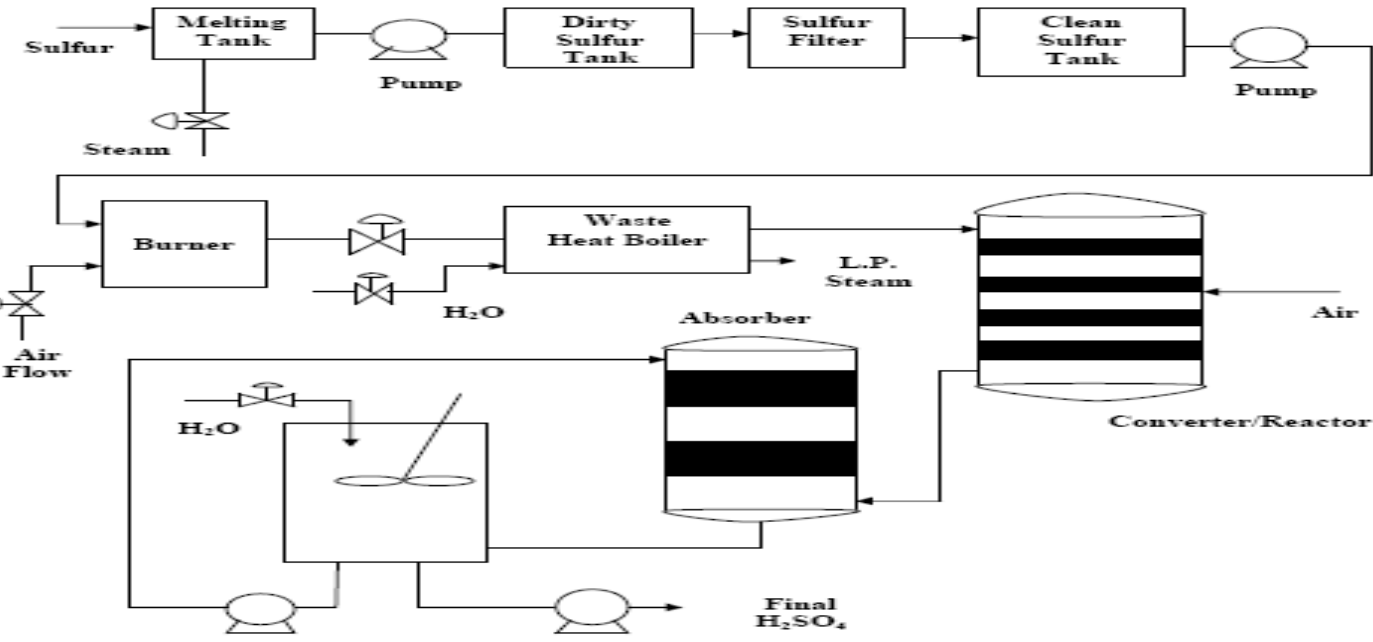

Figure 1: Flow Diagram of Sulfuric acid manufacturing process
$\mathrm{SO}_{3}+\mathrm{H}_{2} \mathrm{O} \rightarrow \mathrm{H}_{2} \mathrm{SO}_{4}$
$\Delta H=-200 \mathrm{~kJ}$ mol-1

The circulating sulfuric acid must be maintained at about $98 \%$ concentration and $70^{\circ} \mathrm{C}$ to maximize the absorption efficiency. The acid strength is important because the vapor pressure of sulfur trioxide above sulfuric acid is at a minimum at an acid strength of $98 \%$ which is depicted in figure 3. At higher concentrations the increased vapor pressure is caused by $\mathrm{SO}_{3}$ and at lower concentrations the water vapor pressure increases sharply and the resultant acid mist is not readily re-absorbed and escapes to the atmosphere.
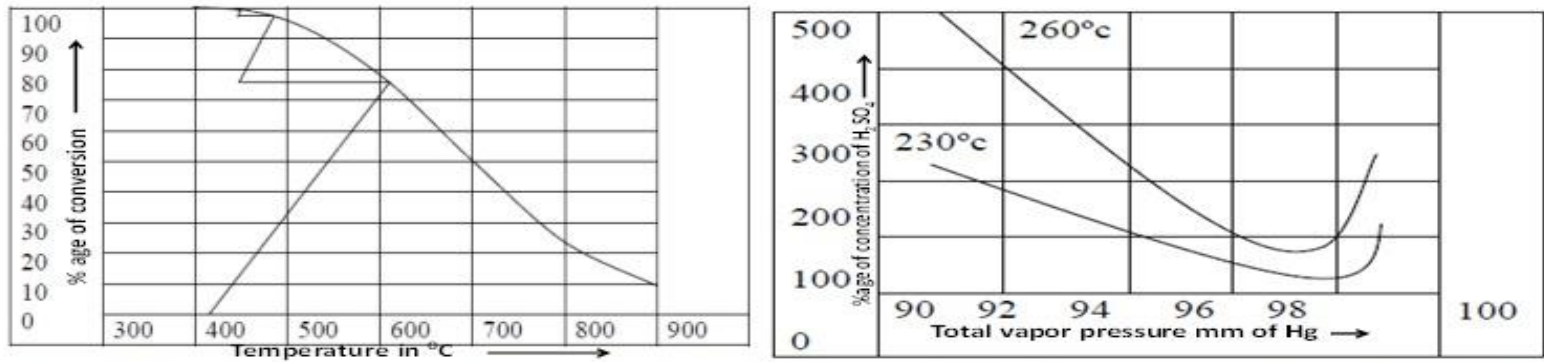

Figure 2: Effect of temperature on the conversion of $\mathrm{SO}_{2}$ into $\mathrm{SO}_{3}$

Figure 3: vapor pressure above sulfuric acid

The sulfuric acid is circulated at such a rate that there is only a very small increase in concentration through the absorber tower. Dilution water is added to the circulating acid tank and also as atmospheric water absorbed in the drying tower. A stream of sulfuric acid is continuously bled off and cooled through a plate heat exchanger before being passed into the storage tanks. The overall conversion from sulfur to sulfuric acid is greater than $98.5 \%$. The plant operates under an air discharge permit which controls emissions of sulfur dioxide and total acidity. Traditionally mild steel has been used as the primary material of construction for process equipment containing $98 \%$ sulfuric acid. The corrosion rate is reasonably low, except at the air/liquid interface where atmospheric moisture encourages corrosion. Raw sulfur is melted and cleaned then it is burnt in the presence of air, here moister contamination prevention is the important criteria. Second is the production of $\mathrm{SO}_{2}$ gas is also important criteria because volume flow and temperature of $\mathrm{SO}_{2}$ gas will decide how the boiler would work, another important point over here is reactor's $1^{\text {st }}$ and $2^{\text {nd }}$ stage temperature which is to be maintained 
Fuzzy logic based automation and control simulation of Sulfuric acid manufacturing process: A case

according to figure shown above. The reactor temperature is important because according to temperature deviation in the all four stage the rate of conversion of sulfuric dioxide to trioxide also get affected. In $3^{\text {rd }}$ step of the process plant the concentration plays a vital role for both sulfuric acids as well sulfur trioxide.

\section{Fuzzy logic control}

Fuzzy logic can be viewed as an extension of multi valued logic system. In two valued logic system a proposition is either true or false. In multi valued logic system a proposition may be true or false or have an intermediate truth value which may be an element of infinite truth valued set. In fuzzy logic, the truth values may range over the fuzzy subset. The fuzzy logic controller is designed to deal with the situations where available source of information are inaccurate, subjectively interpreted or uncertain. The main constitutes of fuzzy controller are Fuzzification, Knowledge base, Rule base, Inference strategy and defuzzification. Figure 4(a) shows the Block diagram of Fuzzy controller. Fuzzification is the process of converting the inputs variable values (sensor signal values) into linguistic variable values or membership function in fuzzy logic sets (fuzzy values). Rule-base of fuzzy logic breaks the control problem down into a series of IF X AND Y THEN Z rules that define the desired system output response for given system input conditions . The number and complexity of rules depends on the number of input parameters that are to be processed and the number of fuzzy variables associated with each parameter[7-8]. Create fuzzy logic membership functions that define the meaning (values) of input/output terms used in the rules. Defuzzification is the process in which output linguistic variable value (fuzzy variable value) is translated into crisp value (real value).

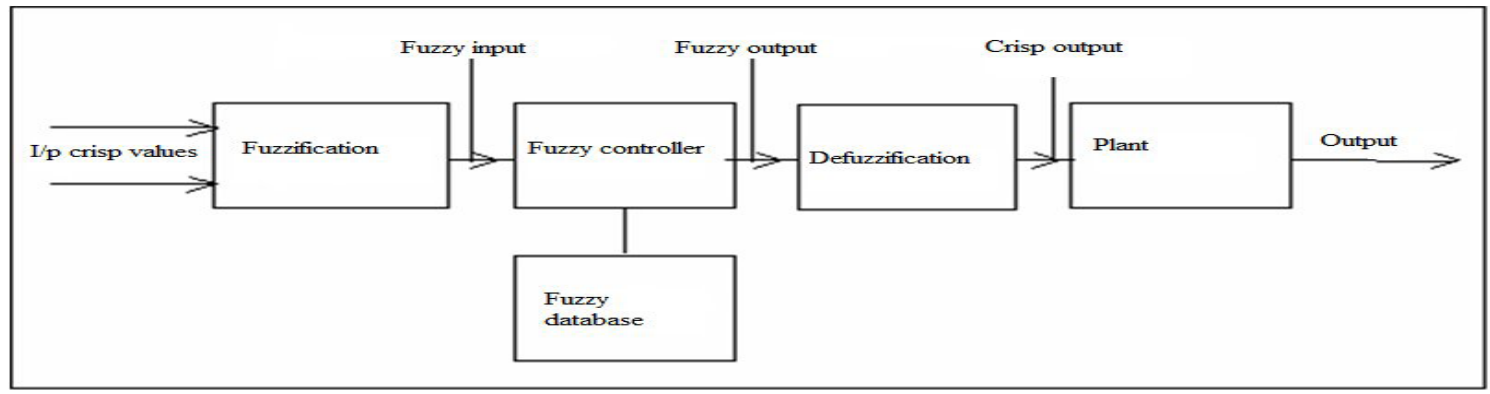

Figure 4(a): Block diagram of Fuzzy Controller

FUZZY TECH SOFTWARE 5.5 is used for the automatic control of sulfuric acid manufacturing process. It contains all the editors, analyzers and tools to design a complete fuzzy logic system. It supports various fuzzy logic inference methods and algorithms. The first step in a fuzzy logic system design is the definition of the system structure. Here, we define the inputs \& outputs of the fuzzy logic system and how they interact. As shown in figure 4(b) the small blocks on the left side are the input interfaces. The input interfaces also contain the fuzzification of the input values. The icon on the left indicates the employed fuzzification method. The small blocks on the right side are the output interfaces that contain the defuzzification method. The larger block in the middle of the screen is the rule blocks. The rule blocks each contain an independent set of fuzzy logic rules. The left column shows the variables used in the precondition of fuzzy rules. The right column shows the variables used for the conclusion of fuzzy rules. The upper box displays the Condition Aggregation Operator. The lower box shows the Result Aggregation Operator.

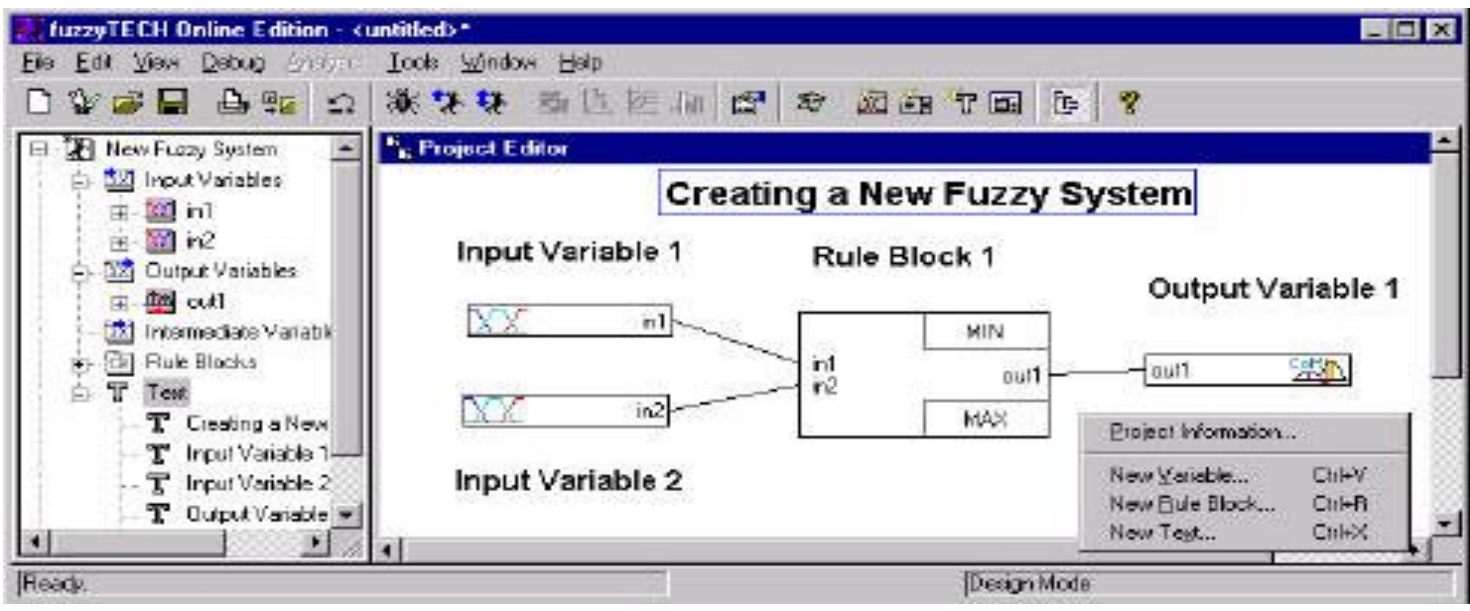

Figure 4(b): Text block explaining object of Fuzzy control system 
Fuzzy logic based automation and control simulation of Sulfuric acid manufacturing process: A case

\section{Process Description for development of fuzzy control strategy:}

The P\&ID diagram of Sulfuric acid manufacturing process has been developed and presented in figure 5. The abbrevation of various instrument and physical variables used in automation and control of sulfuric acid plant has been presented in Table 1. Sulfur is feeded to the sulfur melting tank. Here it is melted with fix temperature steam. Tank's level and temperature would decides whether to feed and how much to feed solid sulfur and steam to the tank. The melted sulfur is pumped to the next tank called dirty sulfur tank. The solid sulfur, which is melted \& converted to the liquid state, having some contamination needed to be removed. So this dirty sulfur is pumped \& passed to the sulfur filter and then to the clean sulfur tank. The MTBM (Mean Time between Maintenance) means the sulfur filter chocking condition would be counted in advance. The pressure switch of sulfur filter will alert the control system when to replace the filter \& between this times production would not be paused though earlier stage pumping would stop, this is due to independency of level parameter of clean sulfur tank.

Step 1: The clean sulfur is pumped to the air burner with respect to clean sulfur tank level, air burner pressure, air burner temperature \& dryer humidity conditions, synchronously air from the dryer faded to the air burner according to sulfur flow to the burner, pressure $\&$ temperature of air burner $\&$ dryer humidity conditions. Dryer is feeded with air coming through filter \& dryer volume is controlled through a pressure switch. Here when dryer humidity crosses its limit, this pause the whole $\mathrm{SO}_{2}$ production process \& further so on. But most of MTBM for changing dryer beds are so set that it wont affects the production process. On the basis of volume flow, temperature of produced Sulfuric Dioxide gas, temperature of boiler \& pressure of boiler, the feed control valve of Sulfuric Dioxide gas to the boiler is controlled. The boiler is waste heat boiler which converts the waste heat produced due to exothermic reaction to the usable steam. The feed water to the waste heat boiler is controlled by the feed water control valve which is dependent of parameters are level, pressure \& temperature of the boiler. In addition temperature of $3^{\text {rd }} \& 4^{\text {th }}$ stage of four stage converter/reactor \& humidity condition of dryer decides the air feeding to those particular stages of converter/reactor.

Step: 2 Sulfuric dioxide gas is converted into sulfuric trioxide gas inside the converter/reactor with the help of vanadium pant oxide catalyst bed. Three parameters, temperature of $1^{\text {st }}$ stage of converter/reactor, temperature and flow of the Sulfuric Dioxide gas coming from the boiler decides feed control to the converter/reactor through the control valve for reactor sulfuric dioxide gas feed control. Cooling of Sulfuric Trioxide gas is needed after passing through $1^{\text {st }}$ stage of reactor because having reaction with vanadium pent oxide $\left(\mathrm{V}_{2} \mathrm{O}_{5}\right)$ sulfuric dioxide's temperature would again rise due to this reaction is also be an exothermic one. The coolant feeded to the heat exchanger for the cooling of this sulfuric trioxide gas is controlled with the coolant flow control valve which is operated on the conditions of the two temperature parameters; these are temperature of $1^{\text {st }}$ and $2^{\text {nd }}$ stage of reactor.

Step3: Concentration of sulfuric trioxide gas coming to two stage absorber, concentration of sulfuric acid, vapor pressure inside $1^{\text {st }}$ stage of absorber \& concentration of sulfuric trioxide gas venting from absorber would decide volume flow of sulfuric trioxide gas entering to a two stage absorber through sulfuric trioxide flow control valve. The unabsorbed sulfuric trioxide gas having less concentration is to be vented and gas having higher concentration is to be recycled, this is done by stopping the feed of sulfuric trioxide coming from reactor \& by stopping vent from absorber with opening of recycle valve. This is done with the help of one three way valve and one recycle valve, one angle and one linear on off type. The operation of these valves would be decided by vapour pressure inside the absorber, concentration of sulfuric acid and concentration of sulfuric trioxide gas being vented from the absorber. The feed rate of dilution water to the high concentration sulfuric acid being stored in the acid circulation tank is decided by level of the acid circulation tank, concentration of sulfuric acid inside the acid circulation tank and flow of high concentration sulfuric acid towards the acid circulation tank. The circulation of lower concentration sulfuric acid is done with the help of circulation pump of which's speed is controlled through level of the acid circulation tank, concentration of sulfuric acid inside that tank and concentration of sulfuric acid of $2^{\text {nd }}$ stage of absorber. The vapor pressure above the sulfuric acid inside the acid circulation tank is controlled through two valves. One valve feed additional air pressure when vapour pressure is lower than desired and one valve vents the vapour by opening when pressure is higher than desired. The pumping of sulfuric acid of desired concentration is pumped to the acid storage tank in accordance to level of both acid circulation and storage tanks and pumping condition of acid circulation pump. And the final output is taken on the basis of level of storage tank with storage tank pump in respect. 
Fuzzy logic based automation and control simulation of Sulfuric acid manufacturing process: A case
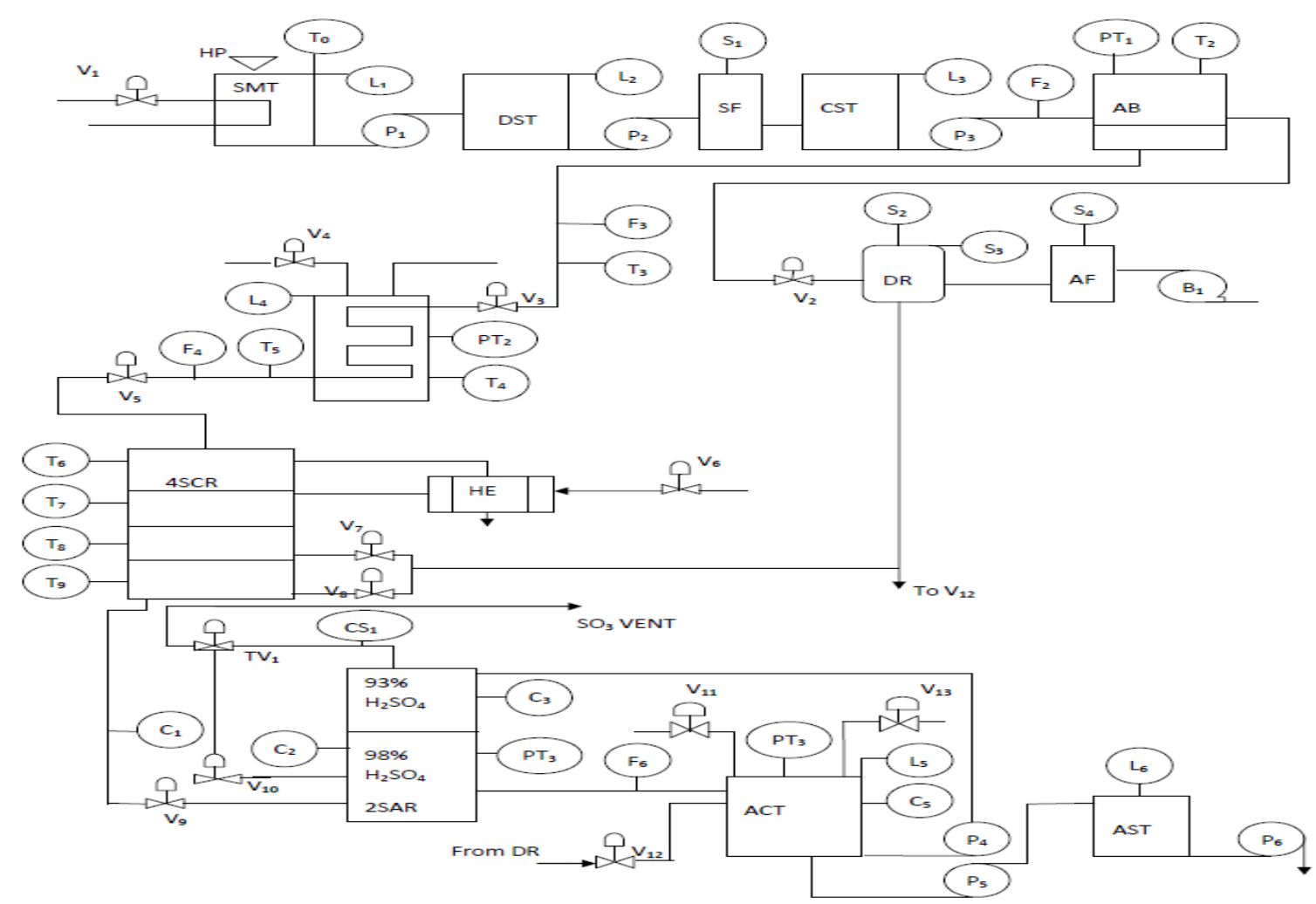

Figure 5: Process Equipment and Instrumentation lay out of the process

Table 1: Abbreniarion of various instrument and physical variables

\begin{tabular}{|c|c|}
\hline \multicolumn{2}{|c|}{ List of Abbreviations \& Specifications } \\
\hline Equipments & Instruments \\
\hline \multicolumn{2}{|l|}{ HP: Hoper for Sulfur Fead 0 to 10 kapax. } \\
\hline SMT: Sulfur Melting Tank & Level All having 0 to $10 \mathrm{ft}$ level \\
\hline DST: Dirty Sulfur Tark & Ll: SMT tanls level \\
\hline SF: Sulfur Filter & L2: DST tank level \\
\hline CST: Clean Sulfur Tarl: & L3: CST tank level \\
\hline AB: Air Bumer with Ash Filter inside & L4: Boiler water level \\
\hline DR: Dryer & L5: ACT tank level \\
\hline AF : Air Filter & L6: AST tank level \\
\hline \multicolumn{2}{|l|}{ WHB: West Heat Boiler } \\
\hline 4SCR: Four Stage Convertor Reactor & Temperature \\
\hline HE: Heat Exchanger & T0: SMT tank temp. 120 to $160^{\circ} \mathrm{C}$ \\
\hline 2SAR: Two Stage Absorber & $\mathrm{T2}: \mathrm{AB}$ temp. 800 to $900^{\circ} \mathrm{C}$ \\
\hline ACT: Acid Circulation Tank & T3: 502 line to boiler temp. 800 to $900^{\circ} \mathrm{C}$ \\
\hline \multirow[t]{2}{*}{ AST: Acid Storage Tank } & T4: Boiler temp. 700 to $900^{\circ} \mathrm{C}$ \\
\hline & T5: SO2 line to 4 SCR temp. 600 to $700^{\circ} \mathrm{C}$ \\
\hline Pumps All having 0 to $500 \mathrm{rpm}$ speed & T6: $1^{12}$ stage temp of $4 S \mathrm{CR}, 825$ to $945^{\circ} \mathrm{C}$ \\
\hline P1:MST pump to DST & $\mathrm{T} 7: 2^{\text {nd }}$ stage temp of $4 \mathrm{SCR}, 625$ to $725^{\circ} \mathrm{C}$ \\
\hline P2: DST pump to CST & T8: $3^{\text {s }}$ stage temp of 4 SCR 450 to $550^{\circ} \mathrm{C}$ \\
\hline P3: CST pump to $A B$ & $\mathrm{~T} 9: 4^{\mathrm{t}}$ stage temp of $4 \mathrm{SCR} .400$ to $450^{\circ} \mathrm{C}$ \\
\hline \multicolumn{2}{|l|}{ B1: Air Suction Draft for dryer } \\
\hline P4:ACT to 2SAR pump & Switches \\
\hline P5:ACT to AST pump & S1: SF pressure switch \\
\hline \multirow[t]{4}{*}{ P6: AST pump for final product out. } & S2: DR humidity switch \\
\hline & S3: DR preasure switch \\
\hline & S4:AF preasure switch \\
\hline & $\begin{array}{l}\text { CS1: Venting SO3 concentration switch } 30 \%=\text { low \& } \\
60 \% \text { = high }\end{array}$ \\
\hline Concentration & Control Valves \\
\hline $\mathrm{C} 1$ : Concentration of $\mathrm{SO} 3$ from $4 \mathrm{SCR} .6096$ to 9096 & V1: Steam for melting aulfur tank \\
\hline $\begin{array}{l}\text { C2: Concentration of Sulfuric acid in } 1^{15} \text { stage of } \\
\text { 2S.AR } 97 \% \text { to } 99 \%\end{array}$ & V2: Air to bumer control valve \\
\hline C3: Concentration of Sulfuric acid in $2^{\text {nd }}$ stage of & V3: $\mathrm{SO}_{2}$ flow control to boiler \\
\hline
\end{tabular}


Fuzzy logic based automation and control simulation of Sulfuric acid manufacturing process: A case

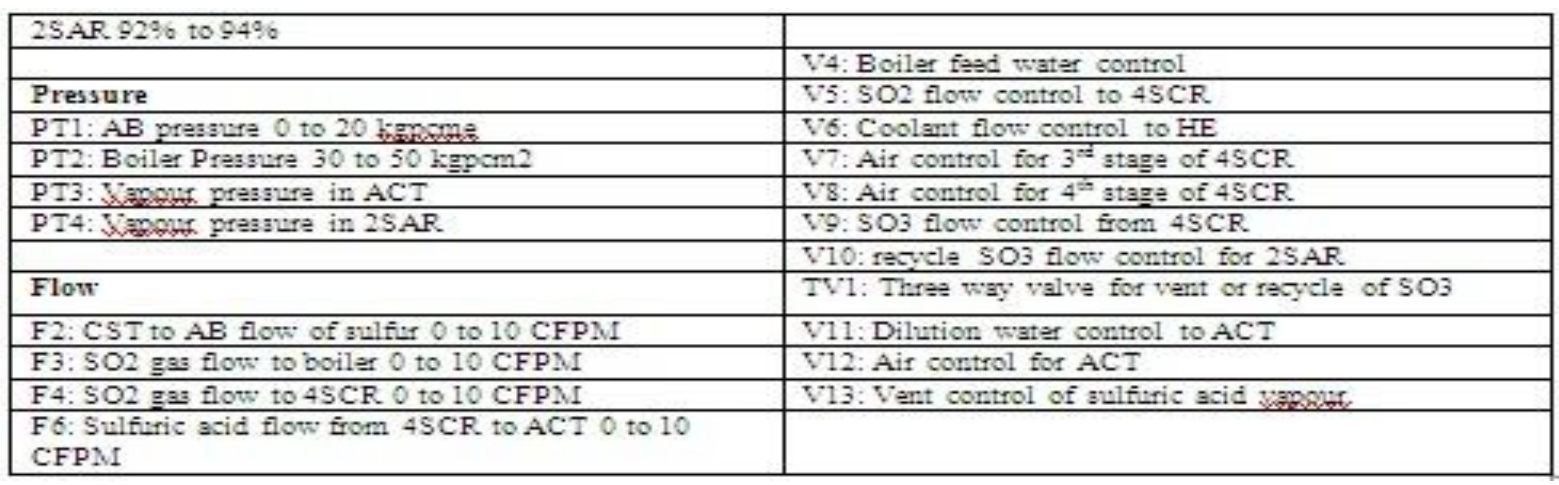

\subsection{Defining Control Loops and Application of Fuzzy Logic for step1}

The complete fuzzy logic based control system for step 1 excluding the controller for control valves $\mathrm{V} 3$ and V4 has been illustrated in figure 6. and the summary of rules for all steps are illustrated in table 2.

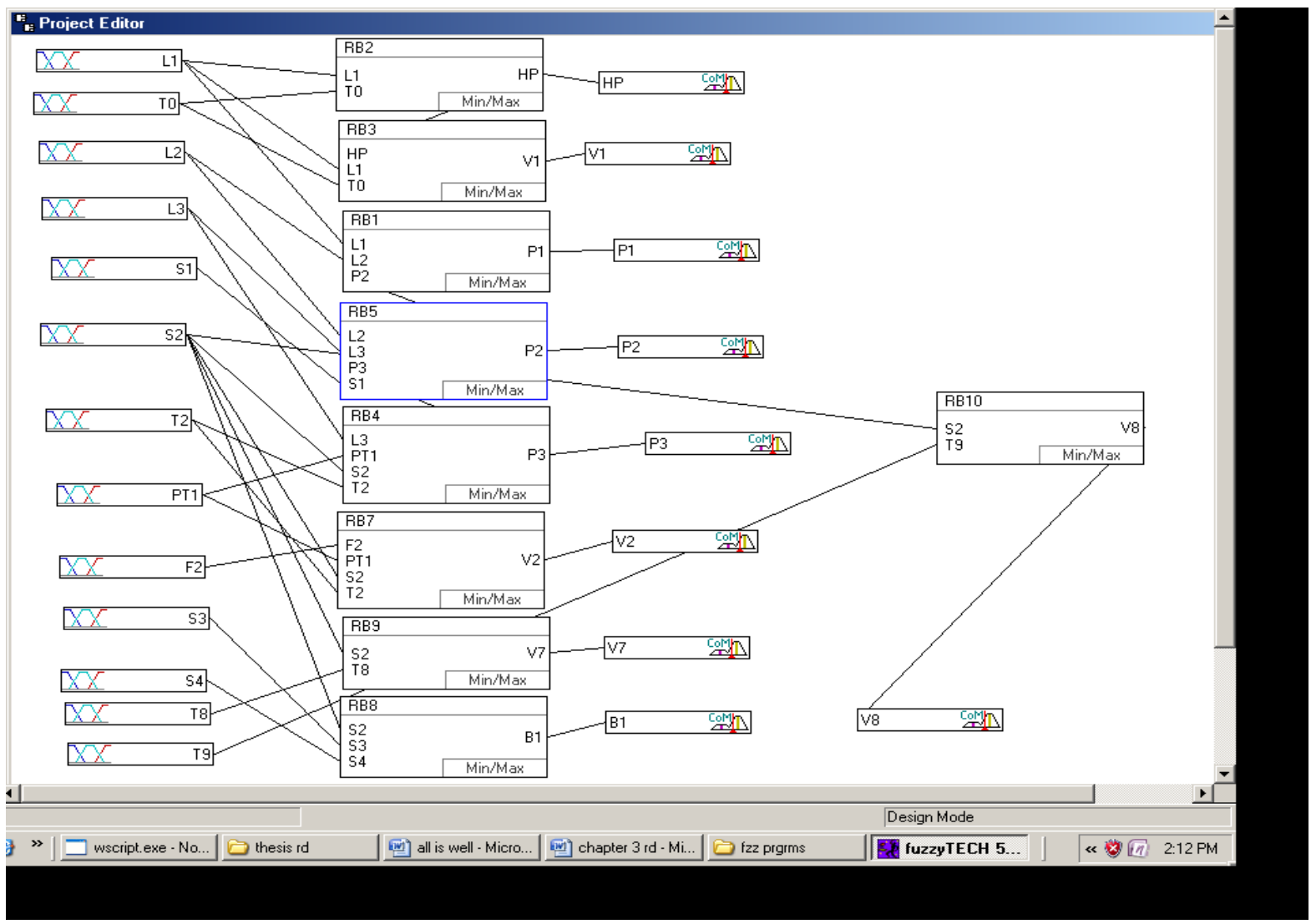

Figure 6: Fuzzy Logic control for Step-1 excluding the control of valves V3 and V4

Table 2: Fuzzy Rules

\begin{tabular}{|c|c|}
\hline \multirow{11}{*}{$\begin{array}{l}\text { For Step } 1 \\
\text { L1 \& T0 THEN HP } \\
\text { L1 \& T0 \& HP THEN V1 } \\
\text { L1 \& L2 \& P2 TEHN P1 } \\
\text { L2 \& L3 \& P3 \& S1 THEN P2 } \\
\text { PT1 \& I } 3 \text { T2 \& S2 THEN P3 } \\
\text { PT1 \& F } 2 \text { \& T2 \& S2 THEN V2 } \\
\text { S4 \& S3 \& S2 THEN B1 } \\
\text { T8 \& S2 THEN V7 } \\
\text { T9 \& S2 THEN V8 } \\
\text { F3 \& T3 \& PT2 \& T4 THEN V3 } \\
\text { L4 \& PT2 \& T4 THEN V4 }\end{array}$} & \multirow{2}{*}{$\begin{array}{l}\text { For Step } 2 \\
\text { F4 \& T5 \& T6 THEN V5 }\end{array}$} \\
\hline & \\
\hline & T7 \& T6 THEN V6 \\
\hline & For Step 3 \\
\hline & C1 \& C2 \& CS1 \& PT4 THEN V9 \\
\hline & C2 \& CS1 \& PT4 THEN TV1 \\
\hline & THEN V10 \\
\hline & L5 \& C5 \& F6 THEN V11 \\
\hline & L5 \& C5 \& C3 THEN P4 \\
\hline & L5 \& PT3 THEN V12 THEN V13 \\
\hline & L5 \& L6 THEN P5 \\
\hline & 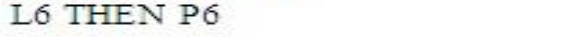 \\
\hline
\end{tabular}


Fuzzy logic based automation and control simulation of Sulfuric acid manufacturing process: A case

(i) HP hoper controls the quantity of solid sulfur being fed into the SMT. Control parameters for SMT are level L1 and temperature T0. Here V1 is the control valve which feeds fix temperature steam to the tank for melting the solid sulfur. So we can define the control Loops over here. The membership function of each are defined in figures 7-10. IF L1 \& T0 THEN HP; IF L1 \& T0 \& HP THEN V1

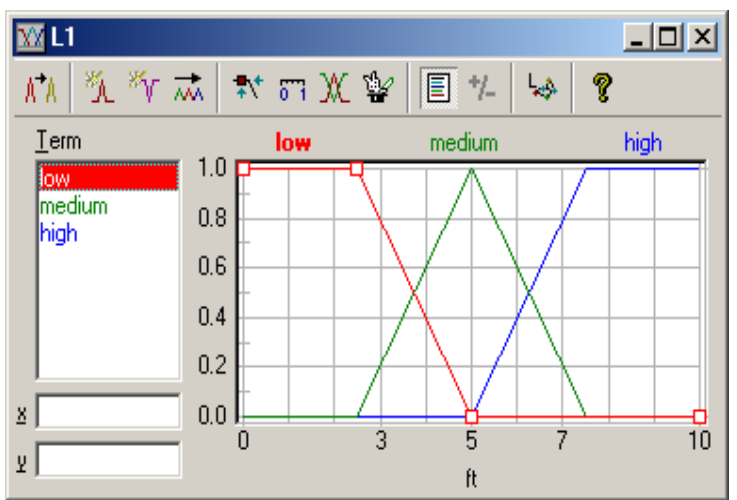

Figure 7: Member ship function of L1

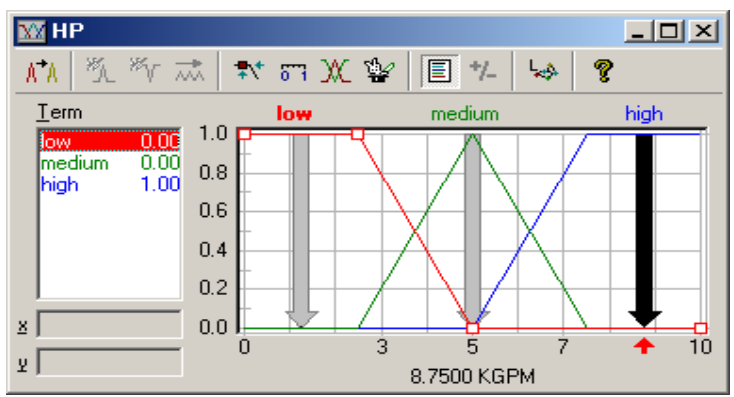

Figure 9: Member ship function of $\mathrm{HP}$

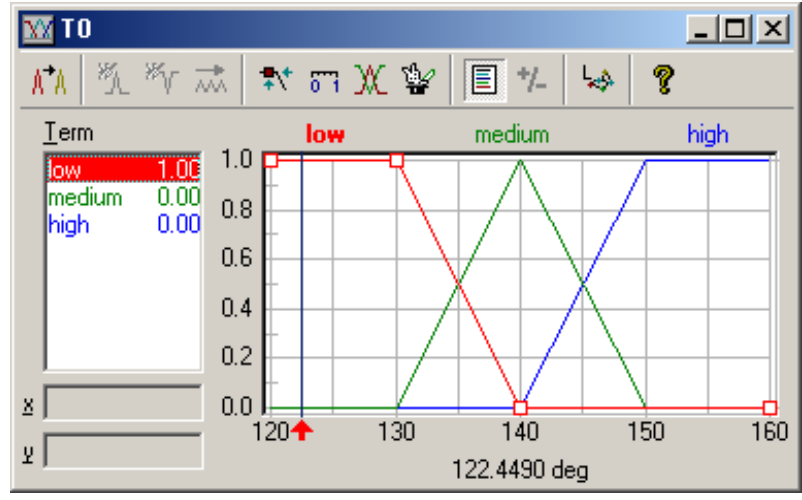

Figure 8: Member ship function of T0

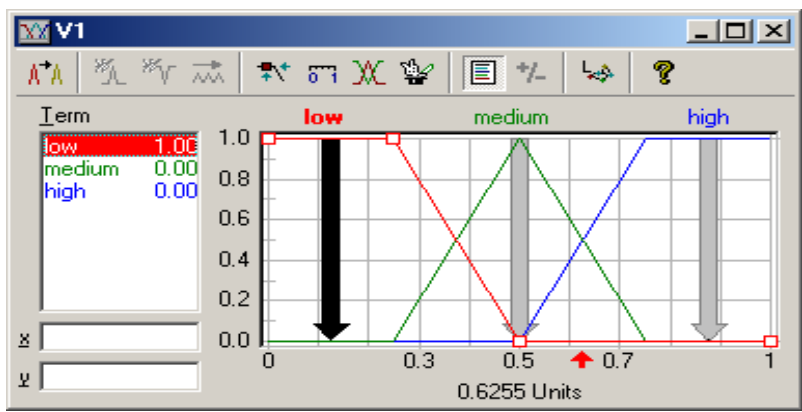

Figure 109: membership function for V1

(ii) Pumping of sulfur is done by three pumps are P1, P2 \& P3. P1 is controlled through parameters L1, L2 \& pump P2 speed conditions. While P2 is controlled through parameters L2, L3, pump P3 speed conditions \& sulfur filter switch S1's conditions. Pump P3 is functioning for sulfur feeding to air burner so it is pumped parameters L3, T2, PT1 \& dryer humidity switch conditions. The membership function of each are defined in figures 11-19. IF L1 \& L2 \& P2 THEN P1; IF L3 \& L2 \& P3 \& S1 THEN P2; IF L3 \& PT1 \& T2 \& S2 THEN P3

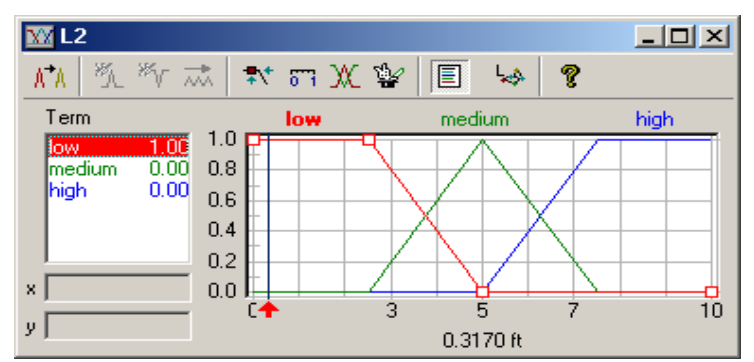

Figure 11: MSF for L2

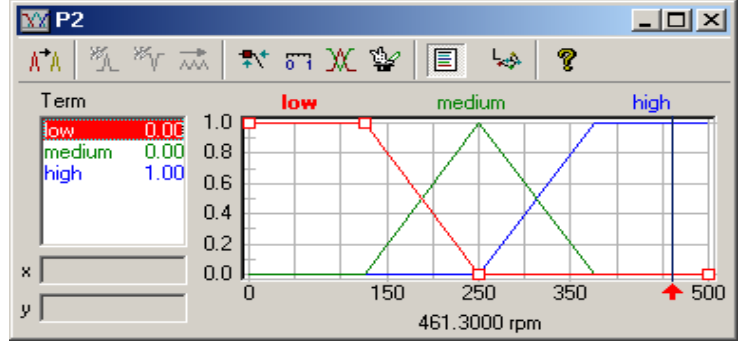

Figure 12: MSF for P2

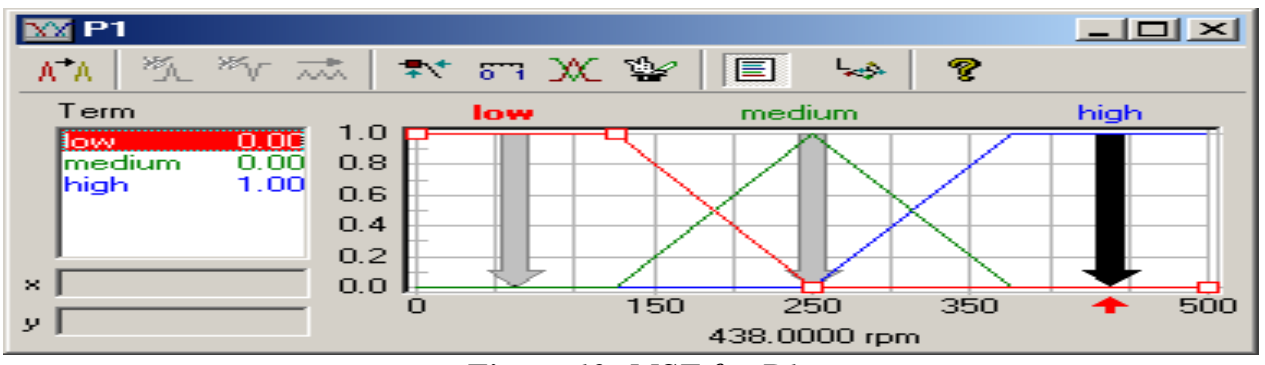

Figure 13: MSF for P1 
Fuzzy logic based automation and control simulation of Sulfuric acid manufacturing process: A case

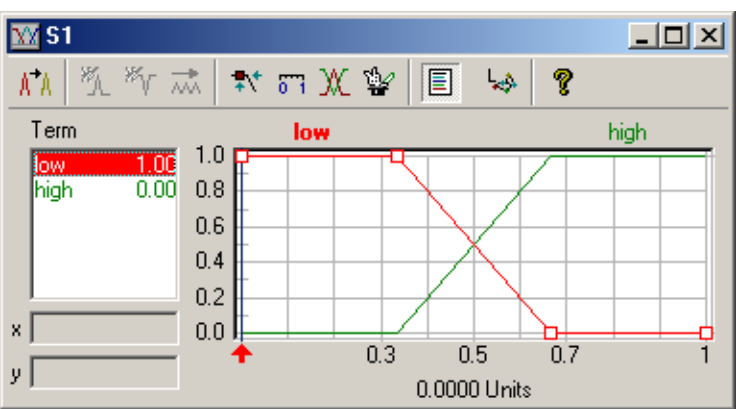

Figure 14: MSF for S1

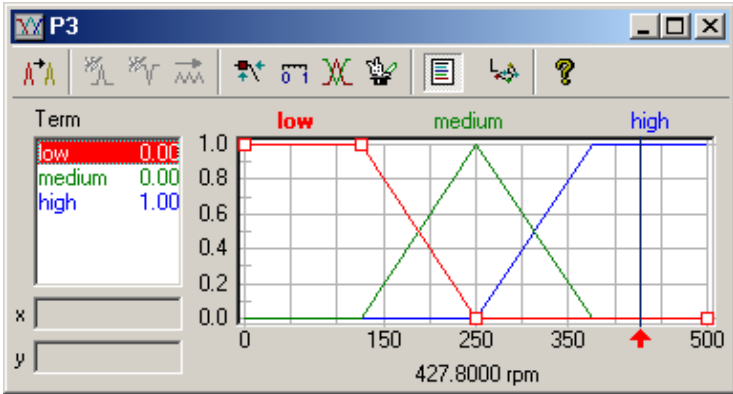

Figure 16: MSF for P3

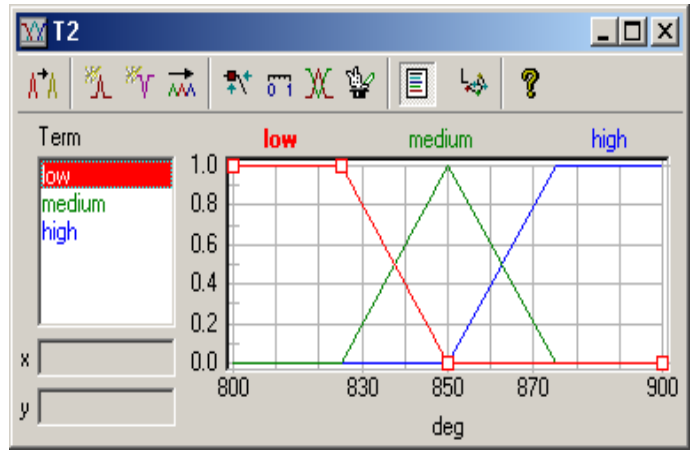

Figure 18: MSF for T2

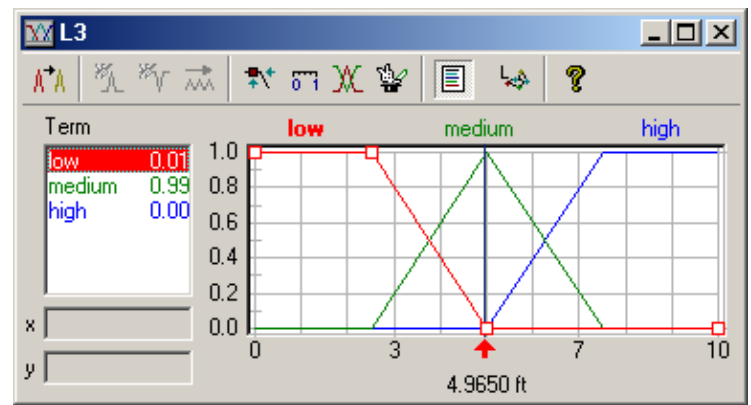

Figure 15: MSF for L3

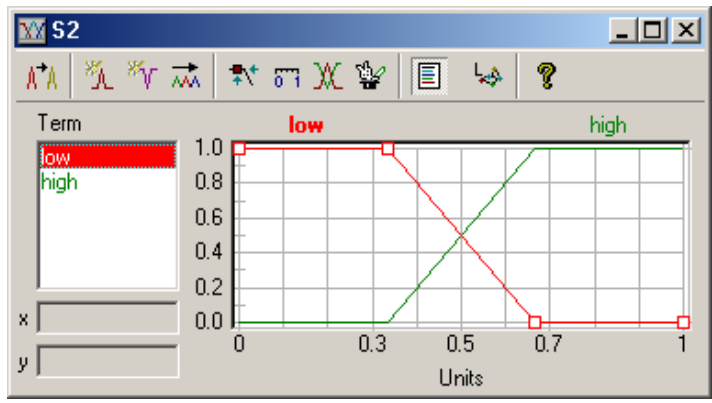

Figure 17: MSF for S2

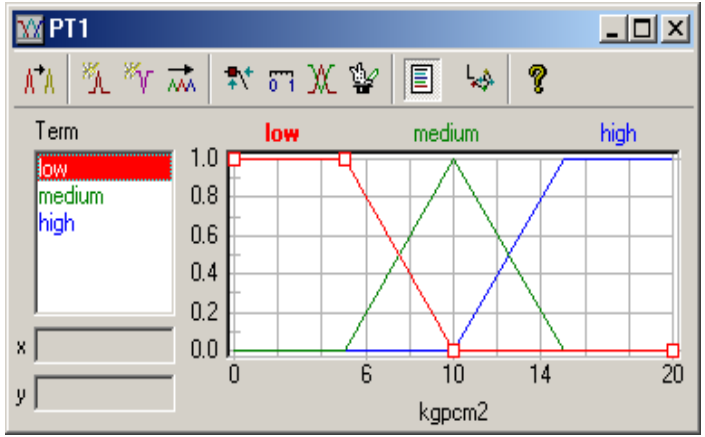

Figure 19: MSF for PT1

(iii) Blower B1 feeds air to dryer and dryer feeds air to Burner via Air to Burner valve V2. B1 depends on humidity S2, Air filter pressure S4 and Dryer pressure S3. While V2 will be operated with sulfur flow F2, Air Burner Pressure PT1 \& Temperature T2 and dryer humidity switch S2. The membership function of each are defined in figures 20-28. IF PT1 \& F2 \& T2 \& S2 THEN V2; IF S4 \& S3 \& S2 THEN B1; IF S2 \& T8 THEN V7; IF S2 \& T9 THEN V8

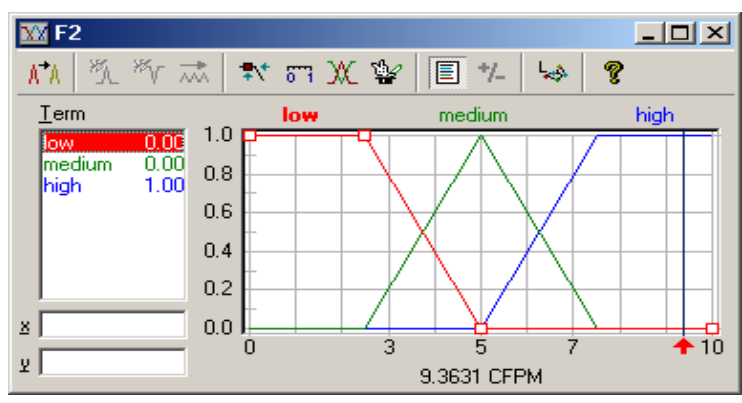

Figure 20: $M S F$ for F2

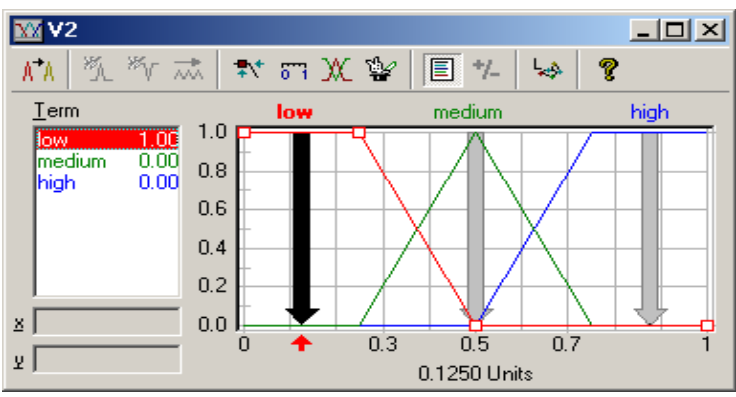

Figure 21: MSF for V2 
Fuzzy logic based automation and control simulation of Sulfuric acid manufacturing process: A case

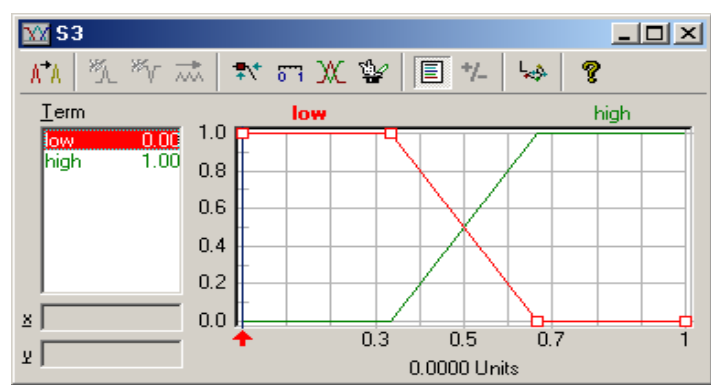

Figure 22: MSF for $S 3$

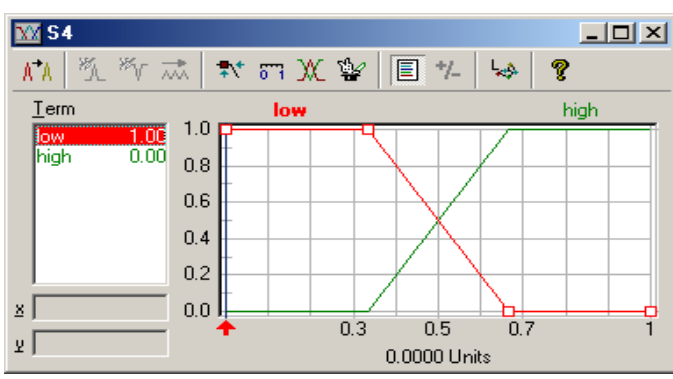

Figure 23: MSF for $S 4$

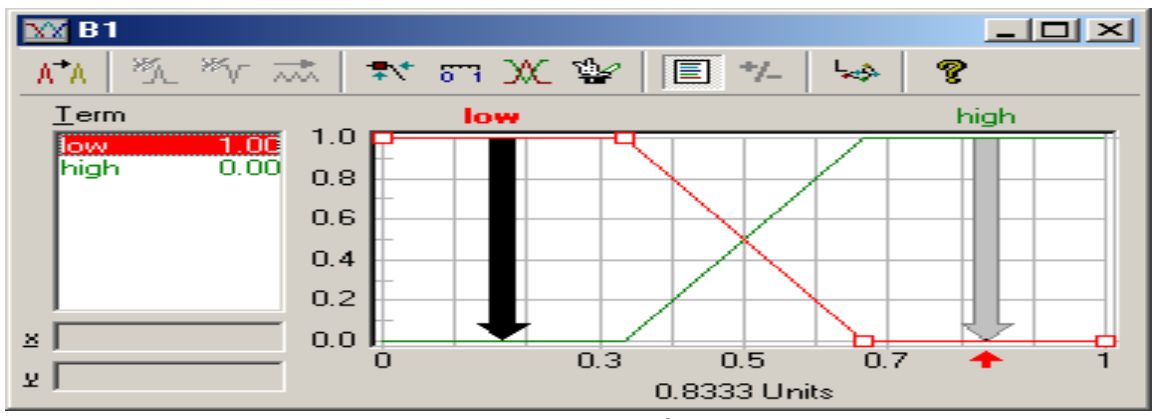

Figure 24: MSF for B1

(iv) $3^{\text {rd }}$ Stage temprature cooling vlave (V7) control of 4SCR

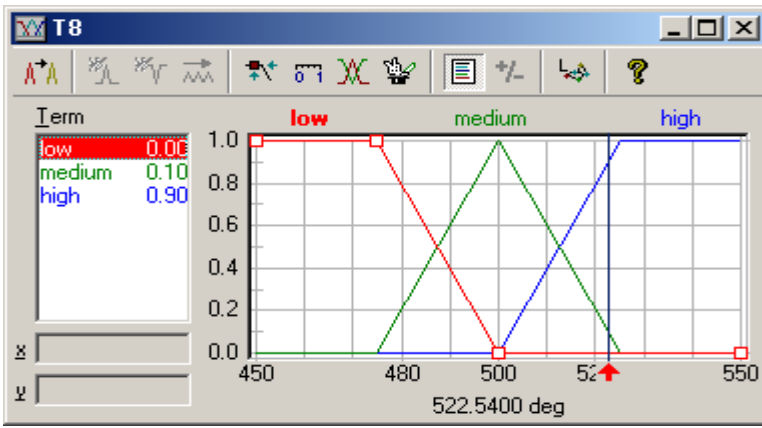

Figure 25: MSF for T8

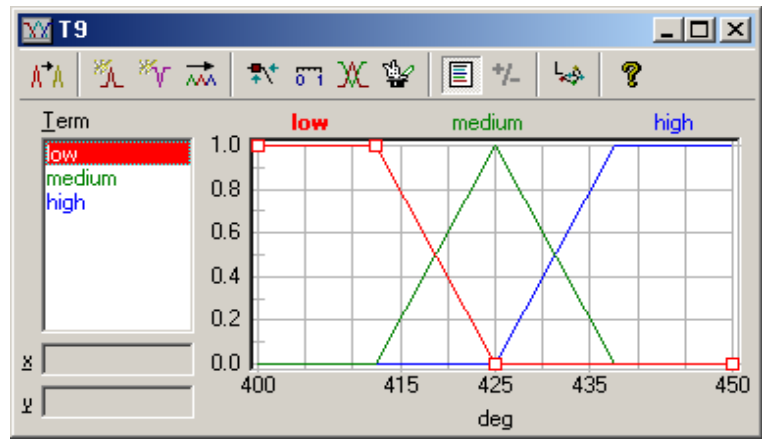

Figure 27: MSF for T9

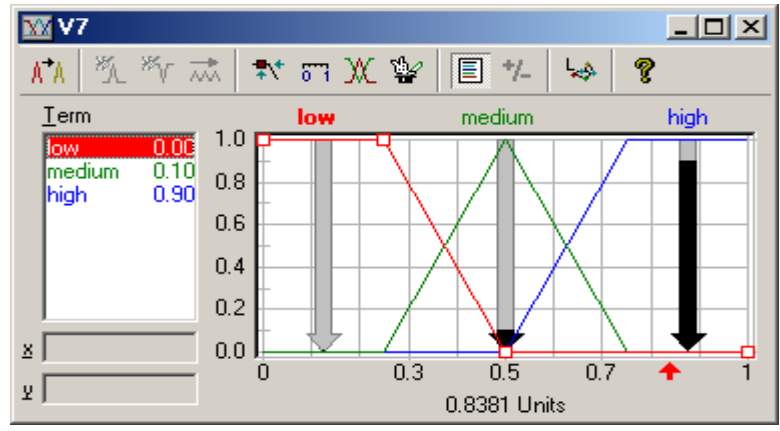

Figure 26:MSF for V7

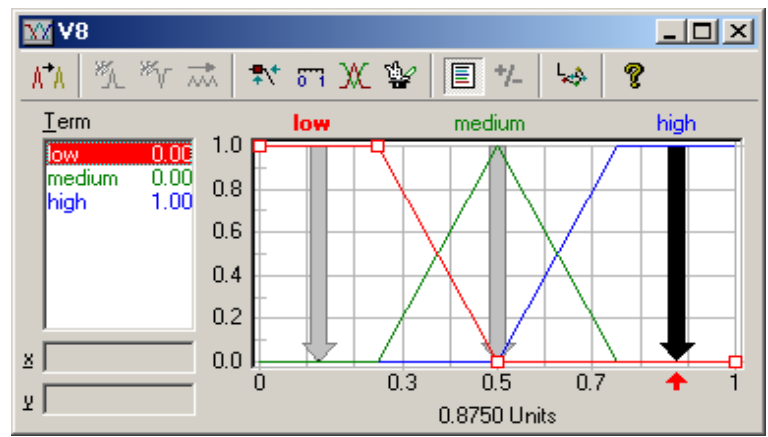

Figure 28: MSF for V8

\subsubsection{Fuzzy Logic Design for Step-1 for controlling control valve V3 \& V4}

(i) Sulfuric Dioxide gas coming from AB will be controlled by its flow F3 \& temperature T3 with Boiler's Pressure PT2 \& temperature T4. The membership function of each are defined in figures 29-33. IF F3 \& PT2 \& T3 \& T4 THEN V3 
Fuzzy logic based automation and control simulation of Sulfuric acid manufacturing process: A case

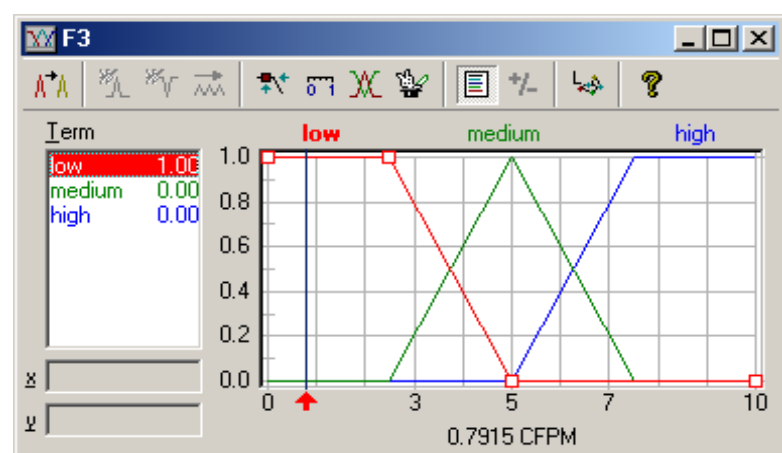

Figure 29: MSF for F3

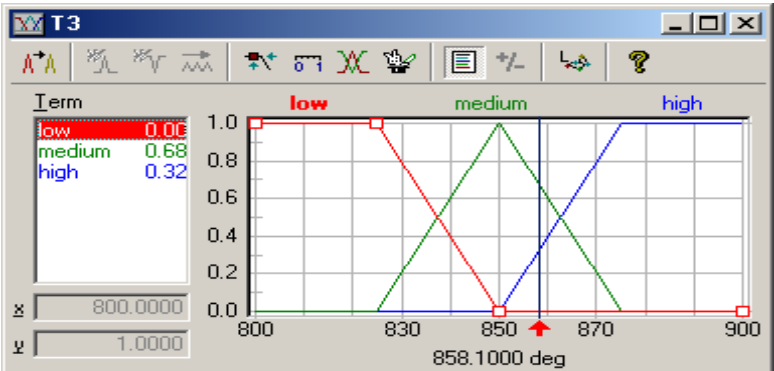

Figure 31: MSF for T3

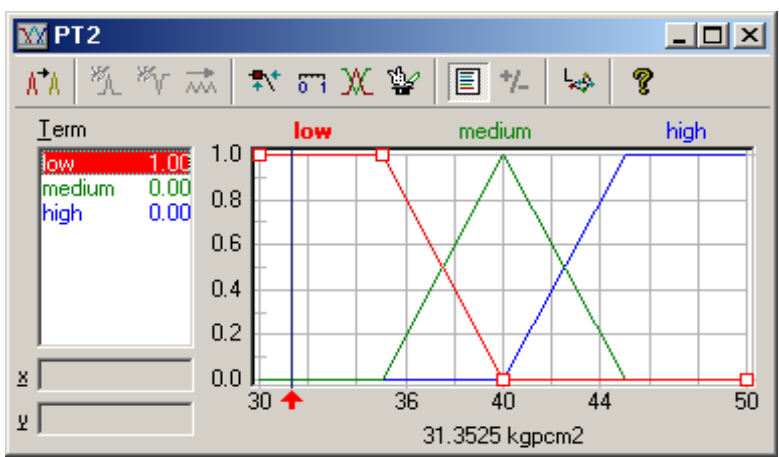

Figure 30: MSF for PT2

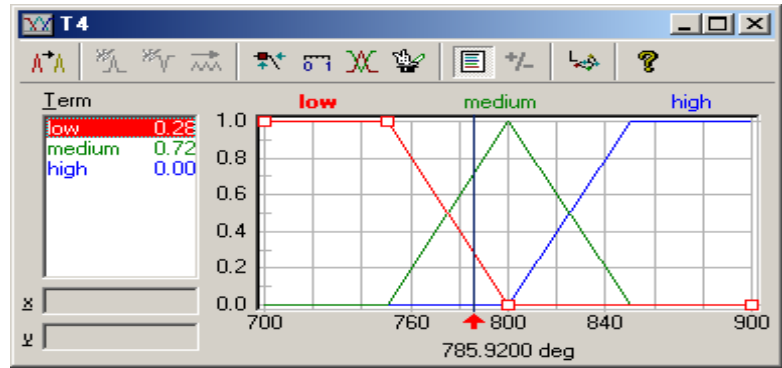

Figure 32: MSF for T4

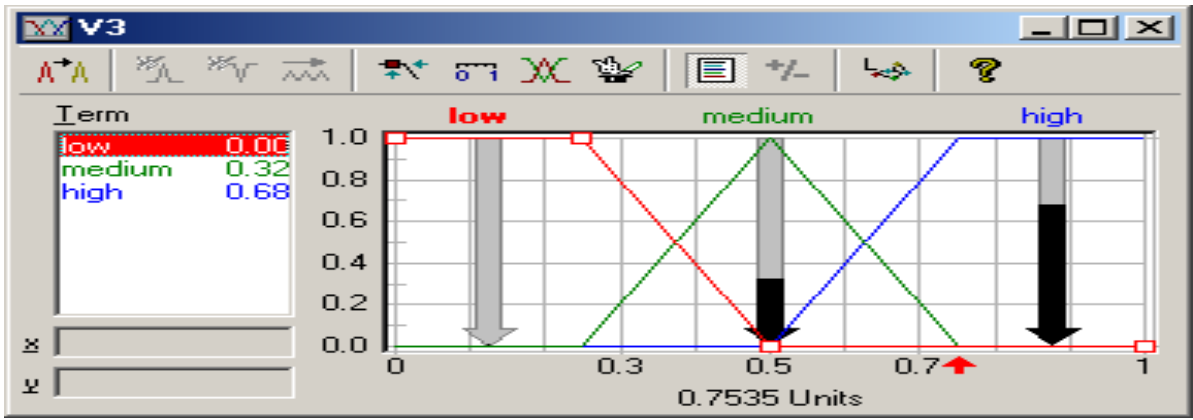

Figure 33: MSF for V3

(ii) Feed water for Waste Heat Boiler is controlled through V4 valve with L4, PT2 \& T4. The membership function of each are defined in figures 34-35. IF L4 \& PT2 \& T4 THEN V4

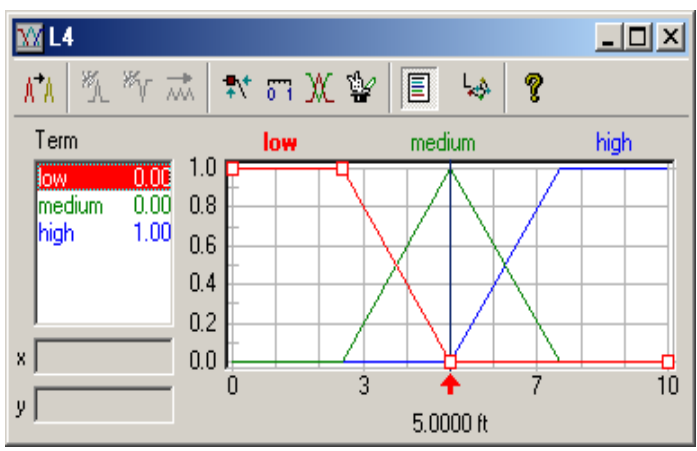

Figure 34: MSF for L4

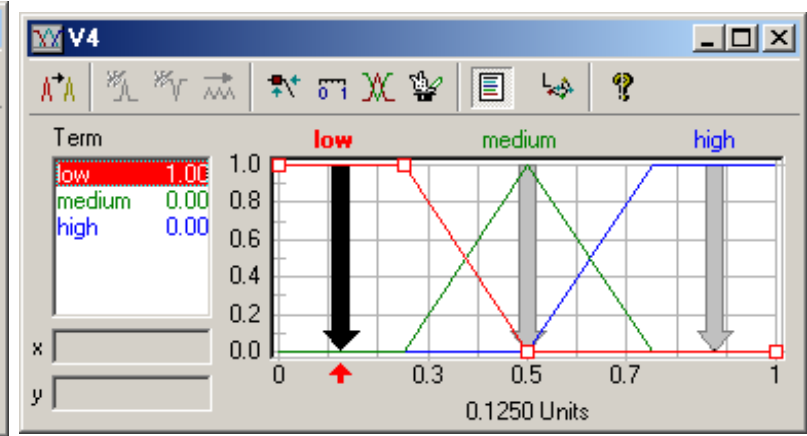

Figure 35: MSF for V4 figure 36 .

The complete Fuzzy Logic Control for Step 1for control of valves V3 \& V4 has been illustrated in 
Fuzzy logic based automation and control simulation of Sulfuric acid manufacturing process: A case

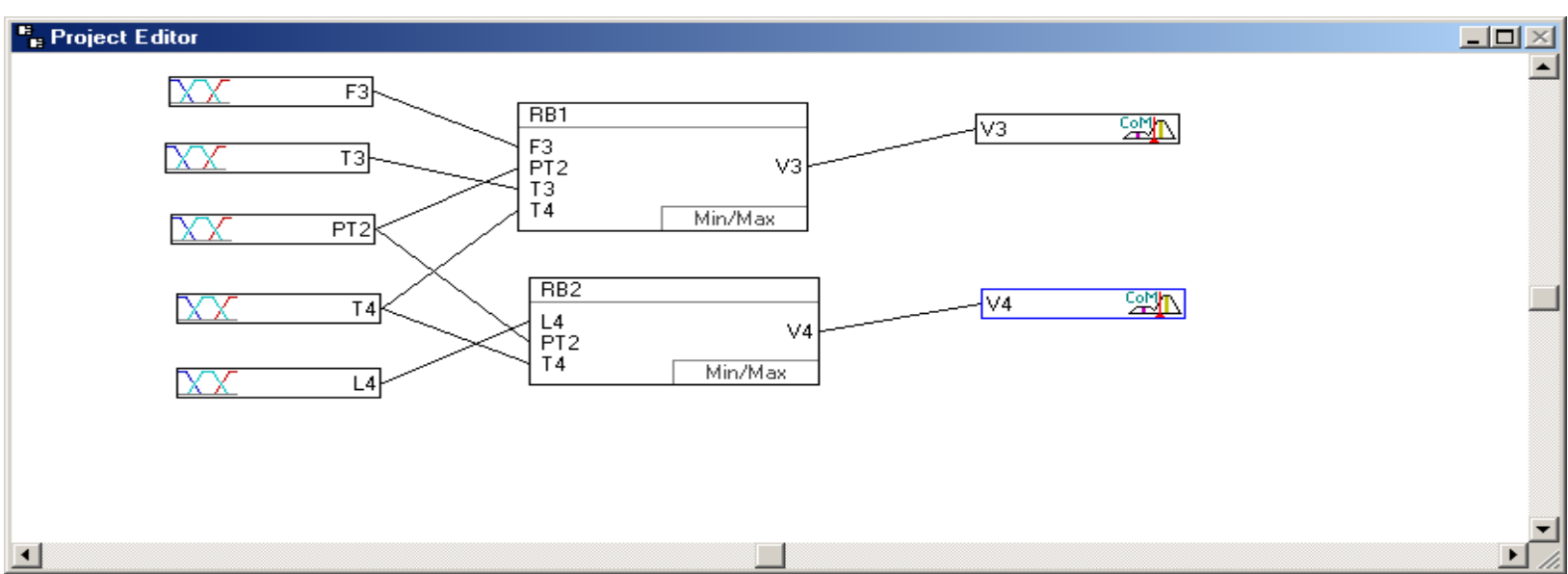

Figure 36: Fuzzy Logic Control for Step 1for control of valves V3 \& V4

4.2. Defining Control Loops and Application of Fuzzy Logic for step2

The complete fuzzy logic based control system for step 2 has been illustrated in figure 37 and the summary of rules for all steps are illustrated in table2.

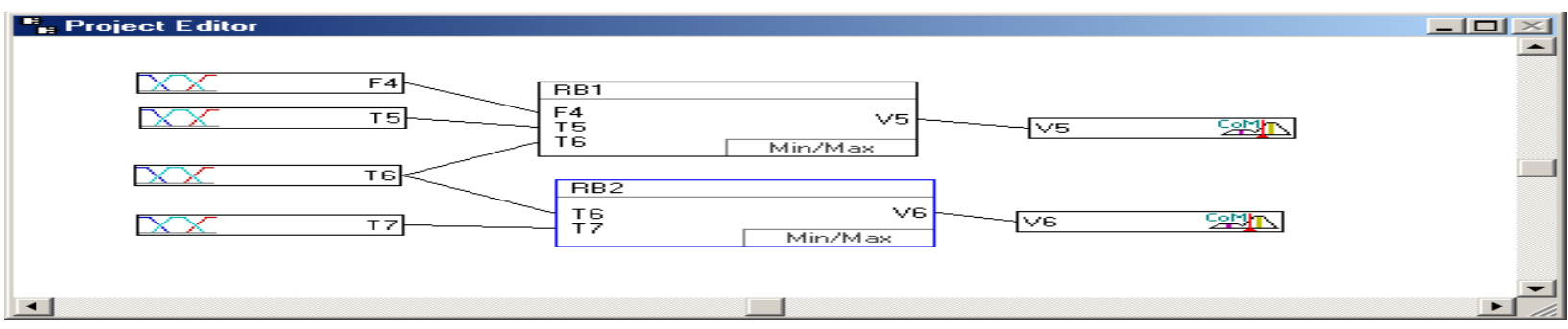

Figure 37: Fuzzy Logic Control for Step 2

(i) Sulfuric dioxide gas from boiler is controlled by its flow F4 \& temperature T5 and temperature of first stage of reactor T6. The membership function of each are defined in figures 38-41.

IF F4 \& T5 \& T6 THEN V5

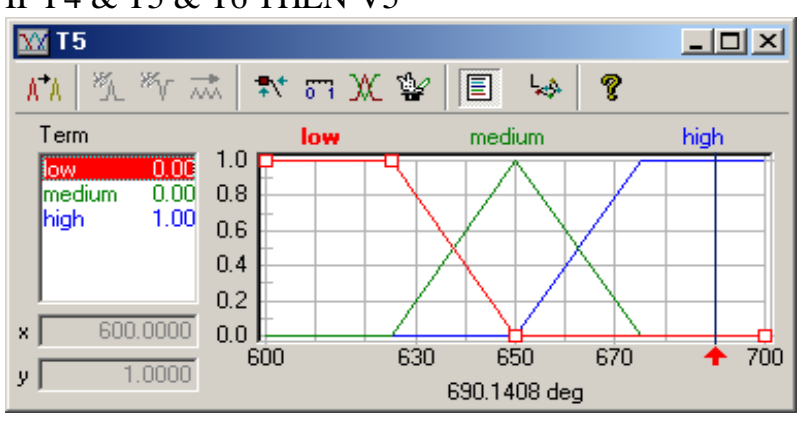

Figure 38: MSF for T5

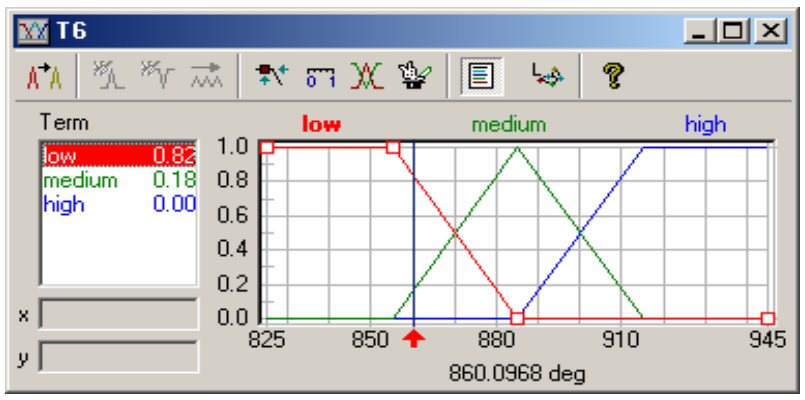

Figure 40: MSF for T6

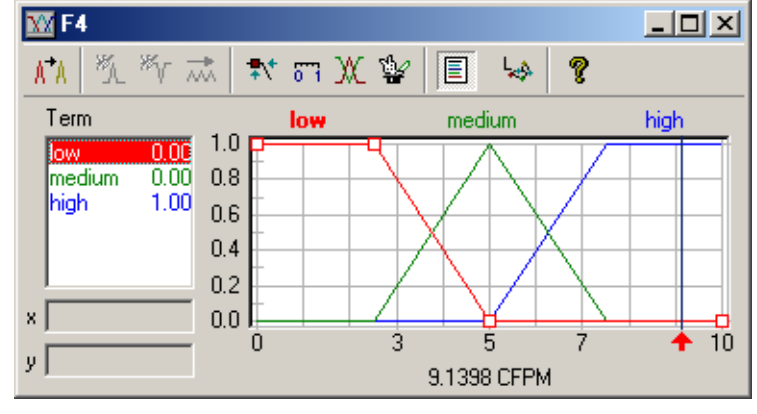

Figure 39: MSF for F4

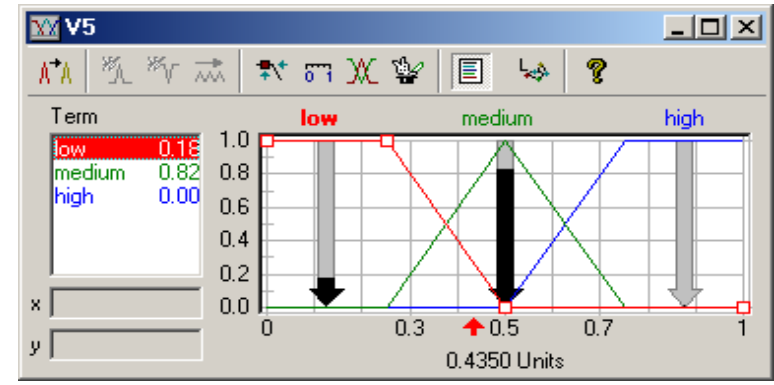

Figure 41: MSF for V5 
Fuzzy logic based automation and control simulation of Sulfuric acid manufacturing process: A case

(ii) The coolant to the Heat Exchanger flow control is done by valve V6 which is dependent on $1^{\text {st }}$ and $2^{\text {nd }}$ stage temperature of reactor. The membership function of each are defined in figures 41-42.

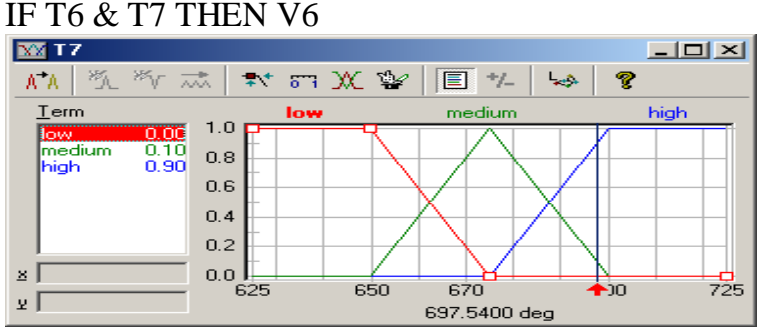

Figure 41: MSF for T7

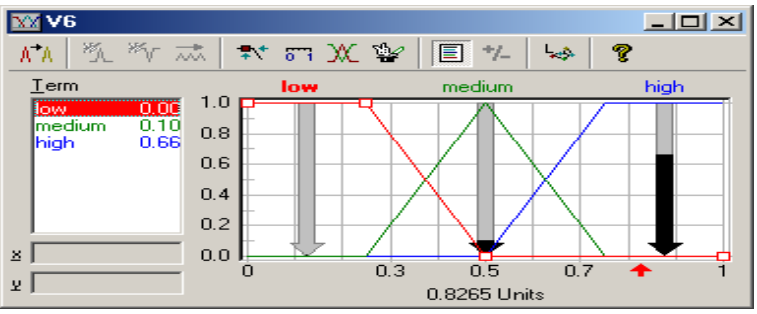

Figure 42: MSF for V6

\subsubsection{Defining Control Loops and Application of Fuzzy Logic for step3: stage1}

(i) Feed Control Valve(V9) for Absorber : Concentrartion of SO3 from reactor and concentration of $\mathrm{H}_{2} \mathrm{SO}_{4}$ \& vapour pressure inside absorber with venting $\mathrm{SO}_{3}$ concentratioh are parameters to control V9 valve. The membership function of each are defined in figures 43-47. IF C1 \& C2 \& CS1 \& PT4 THEN V9

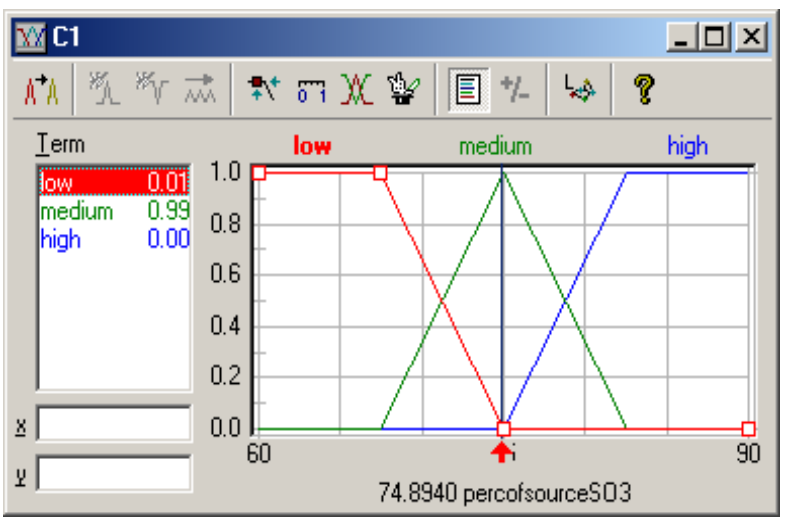

Figure 43: $M S F$ for $C 1$

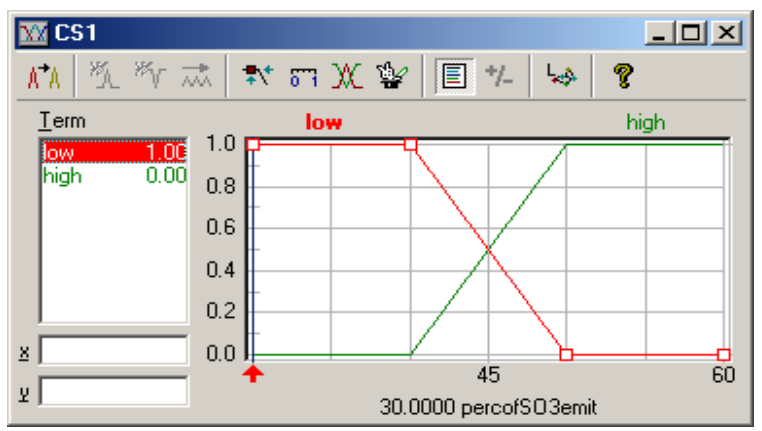

Figure 45: MSF for CS1

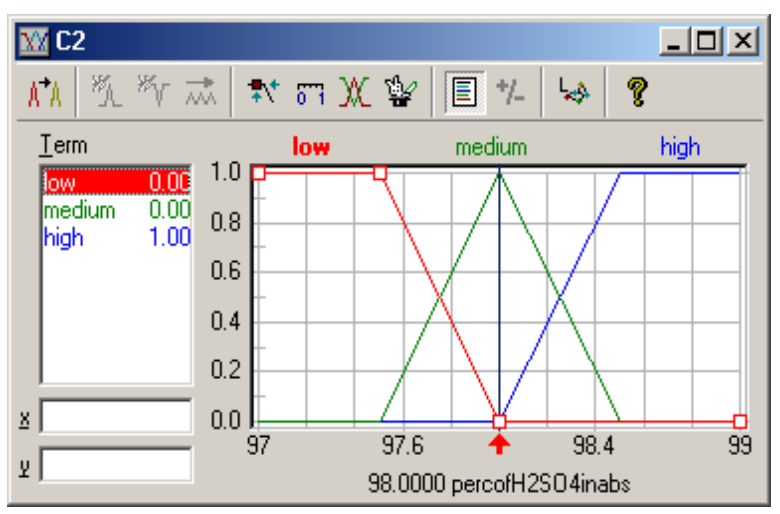

Figure 44: MSF for C2

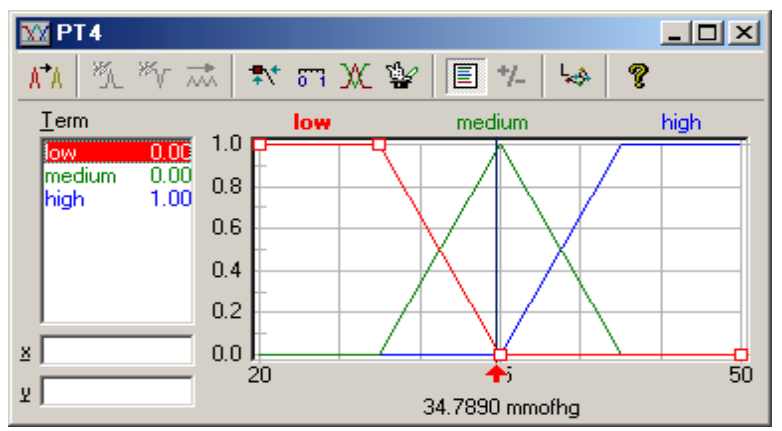

Figure 46: MSF for PT4

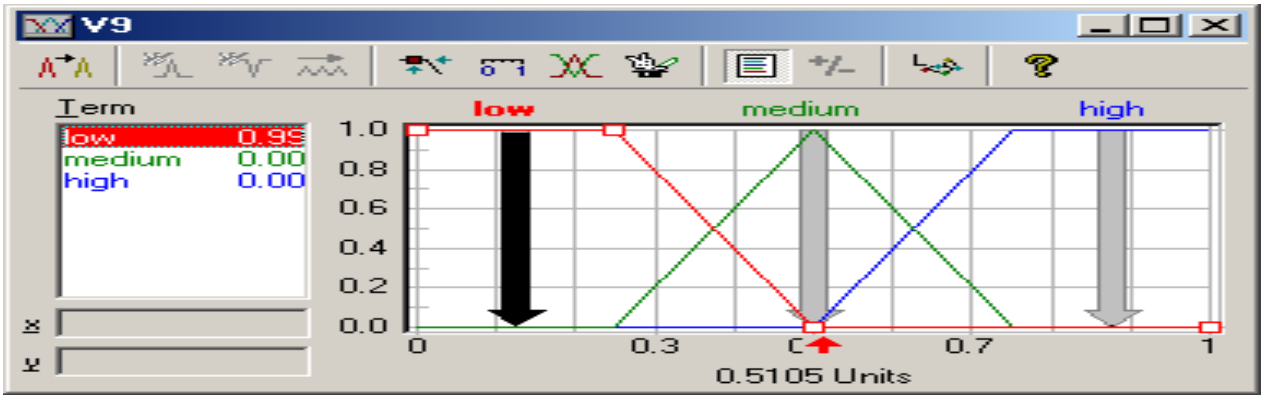

Figure 47: MSF for V9

www.iosrjen.org 
Fuzzy logic based automation and control simulation of Sulfuric acid manufacturing process: A case

The fuzzy project editor for Feed Control Valve(V9) for Absorber is illustared in figure49.

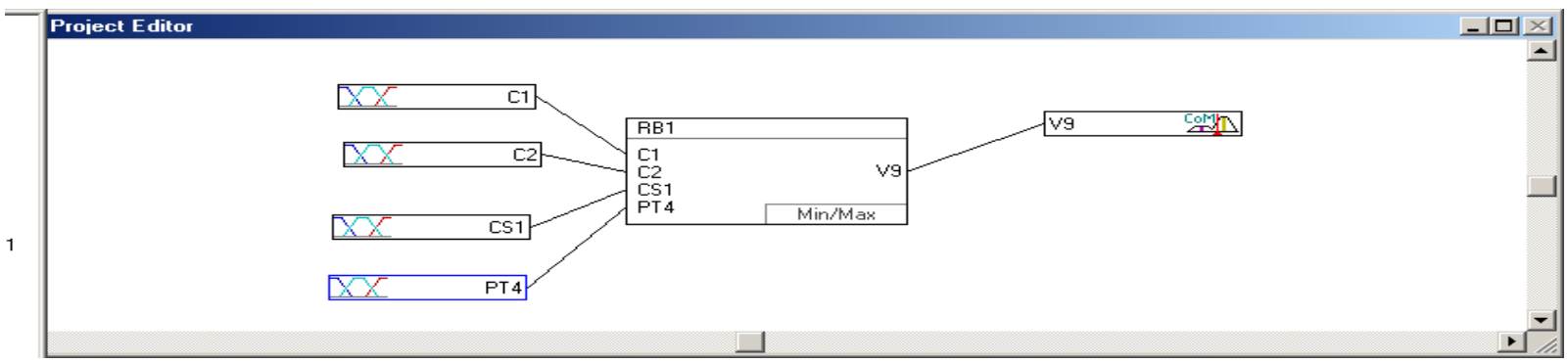

Figure 49: Project Editor for V9

(ii) Fuzzy Control System for Absorber feed and Vent control

Low concentration and unabsorbed Sulfuric Trioxide gas should be vent in the atmosphere and higher concentration should be recycled. This is done by one three way valve and one on-off type valve. The membership function of each are defined in figures 50-51.

IF C2 \& CS1 \& PT4 THEN TV1 THEN V10

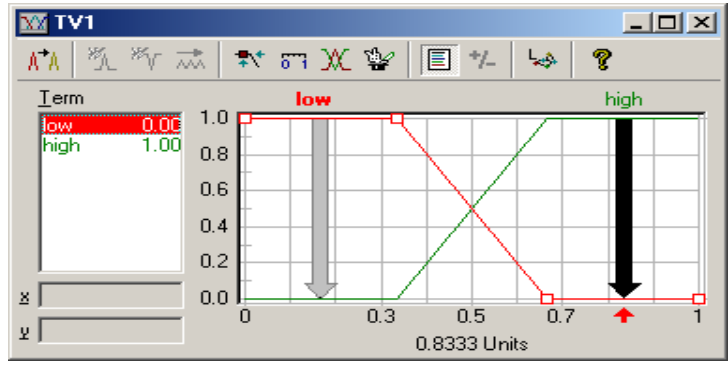

Figure 50: MSF for TV1

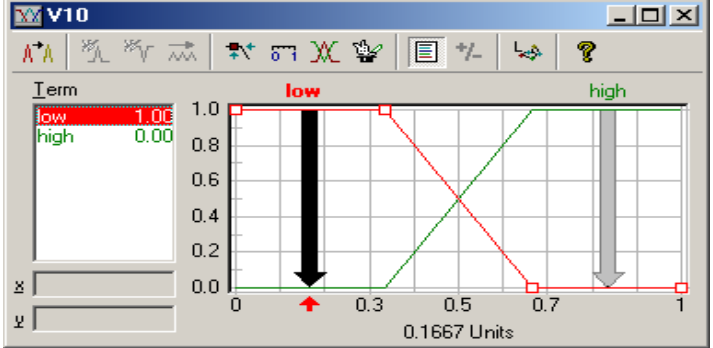

Figure 51: MSF for V10

The fuzzy project editor for Absorber feed and Vent control is illustared in figure 52.

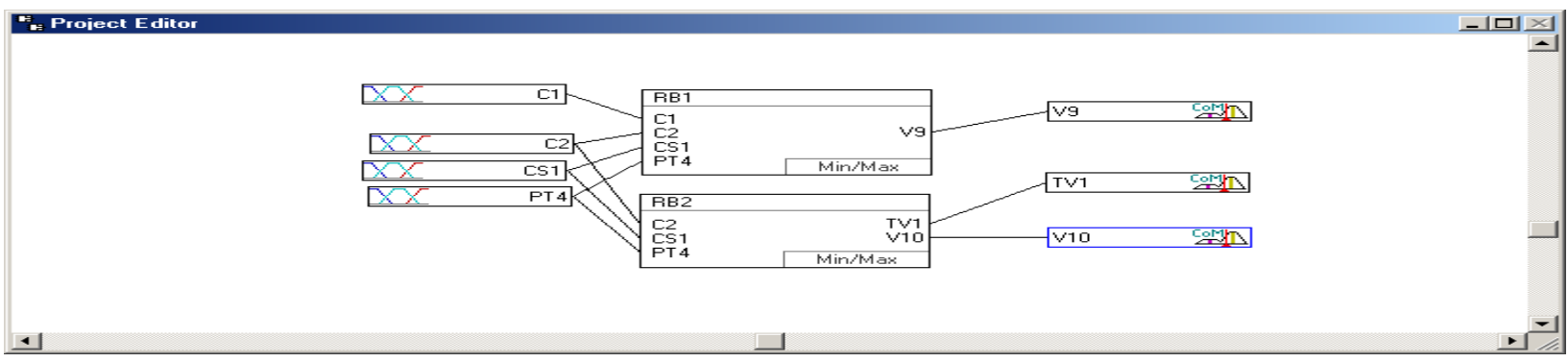

Figure 52: Fuzzy Control System for Step 3 stage one

4.3.2. Defining Control Loops and Application of Fuzzy Logic for step3: stage2

(i) Concentration of sulfuric acid inside circulation tank and tanks level and flow of sulfuric acid towards tank are the parameters to control V11. The membership function of each are defined in figures 53-56.

IF C5 \& L5 \& F6 THEN V11

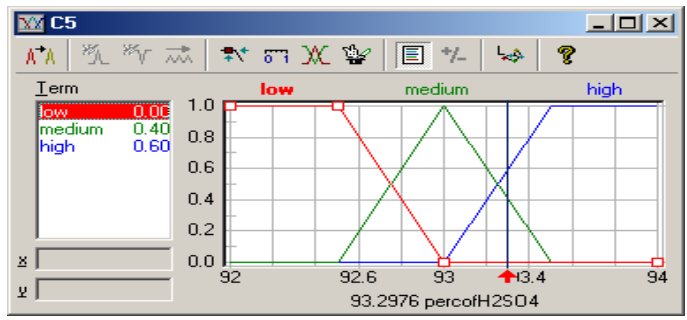

Figure 53: MSF for C5

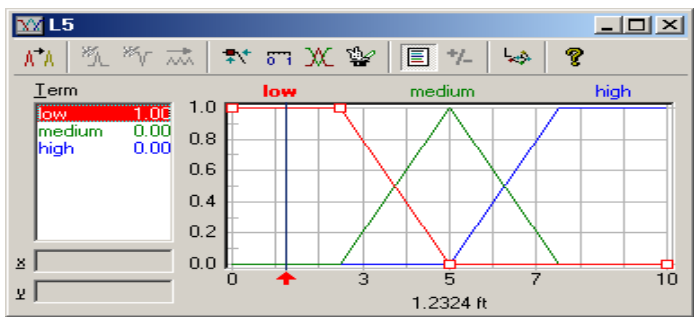

Figure 54: MSF for L5 
Fuzzy logic based automation and control simulation of Sulfuric acid manufacturing process: A case

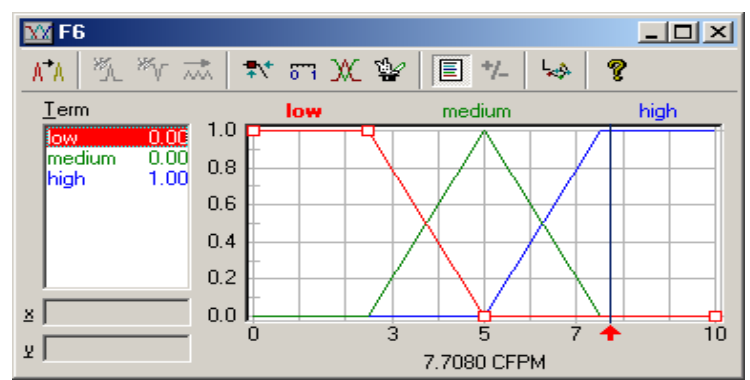

Figure 55: MSF for F6

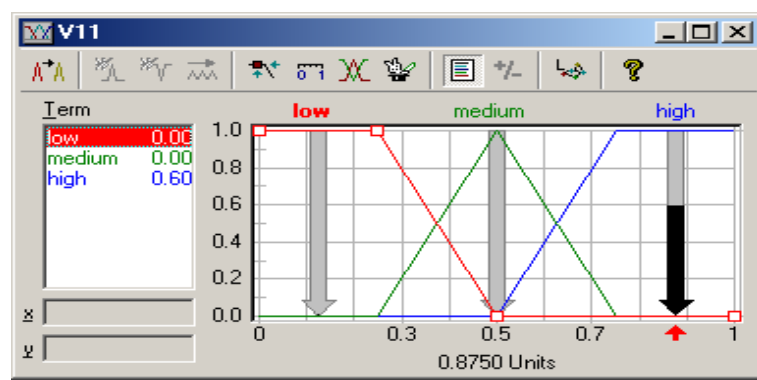

Figure 56: MSF for V11

(ii) Pump for acid circulation is controlled by the circulation tank's concentration and level with concentration of sulfuric acid inside $2^{\text {nd }}$ stage of absorber. The membership function of each are defined in figures 57-58. IF C3 \& C5 \& L5 THEN P4

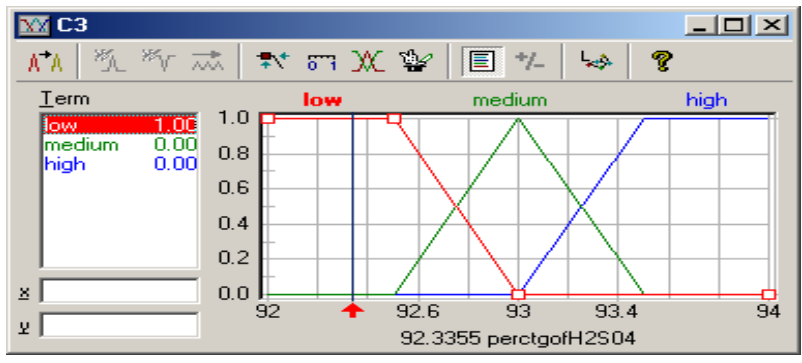

Figure 57: MSF for C3

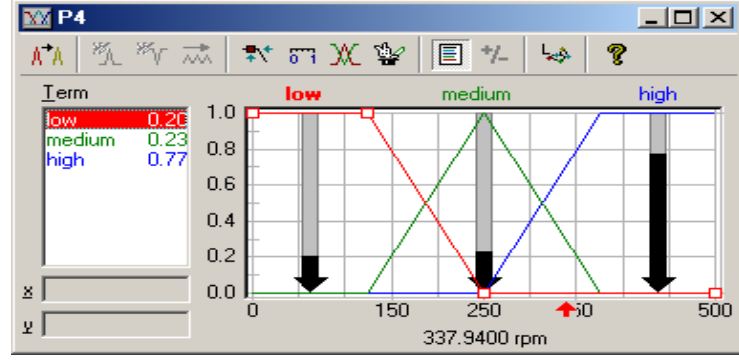

Figure 58: MSF for P4

(iii) For Vapour Pressure control inside the Acid Circulation Tank Two valves used, one (V13) is for venting vapour fume with high pressure and by other (V12) inserting air and generating pressure. The membership function of each are defined in figures 59-61. IF L5 \& PT3 THEN V12 THEN V13

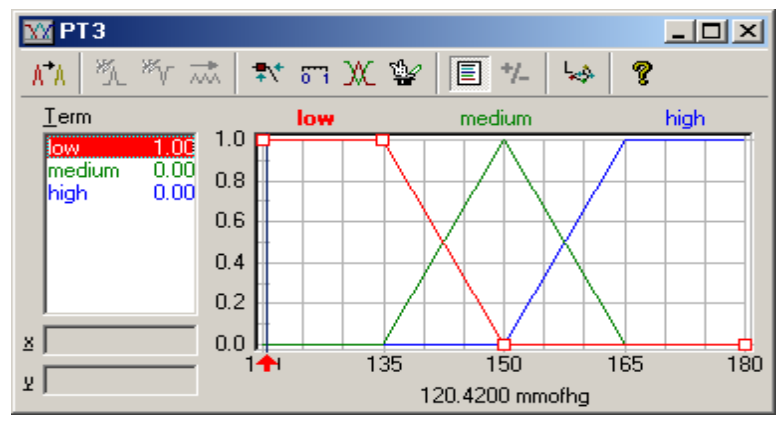

Figure 59: MSF for PT3

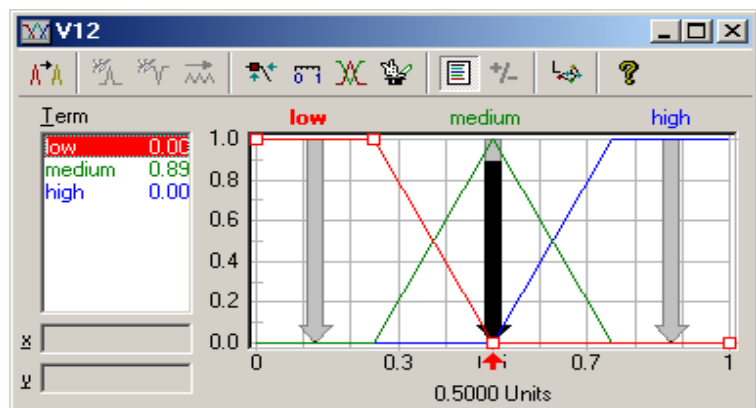

Figure 60: MSF for V12

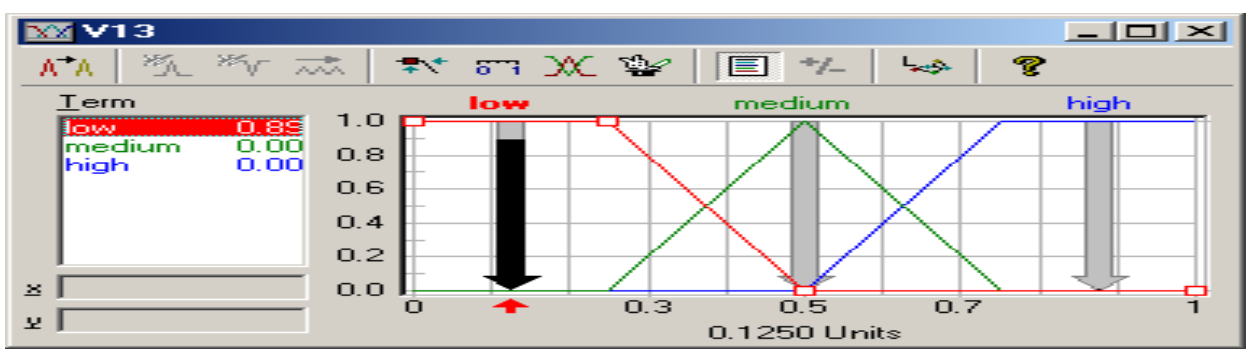

Figure 61: MSF for V13

(iv) Storage Tank's pump runs on level of circulating and storage tank's level and circulating pump's speed condition. The membership function of each are defined in figures 62-64. IF L5 \& L6 \& P4 THEN P5 
Fuzzy logic based automation and control simulation of Sulfuric acid manufacturing process: A case

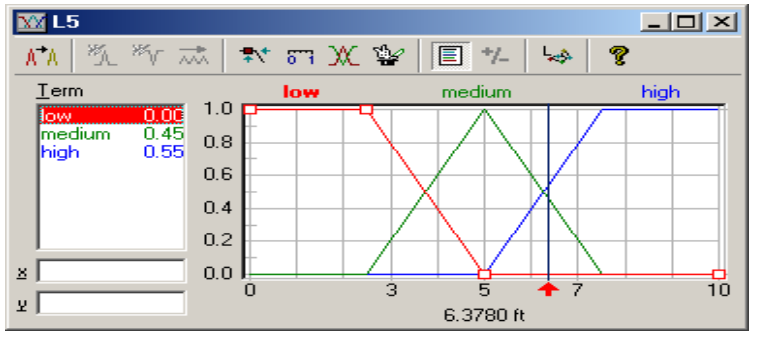

Figure 62: MSF for L5

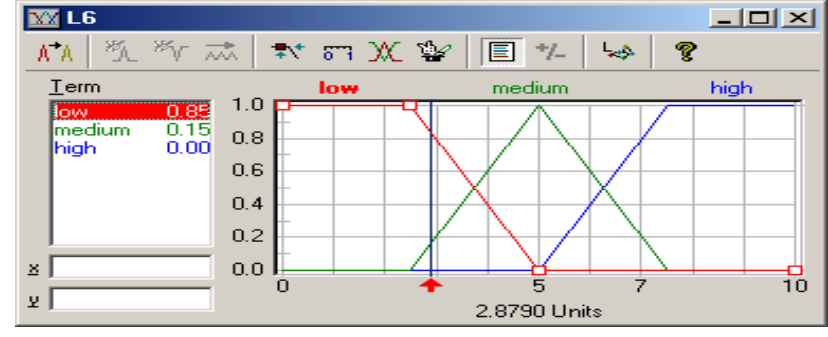

Figure 63: MSF for L6

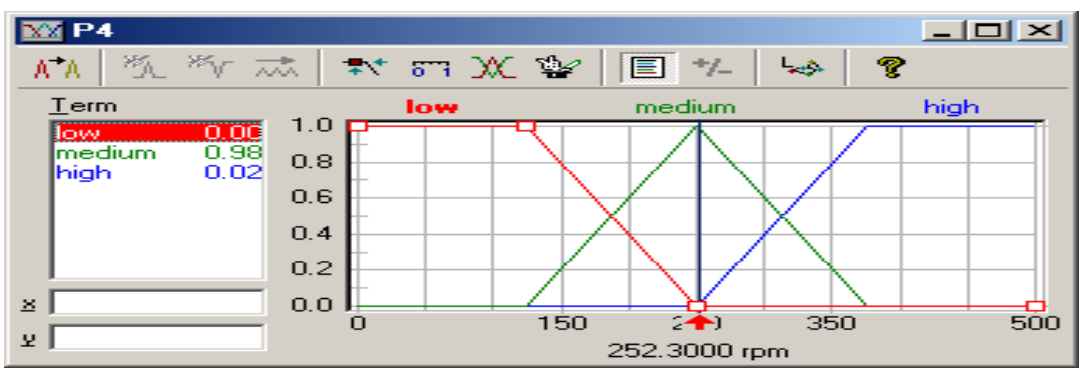

Figure 64: MSF for P4

(v) Storage Tank gives the output through its pump according to level of storage tank. The membership function of P6 is defined in figures 65. IF L6 THEN P6

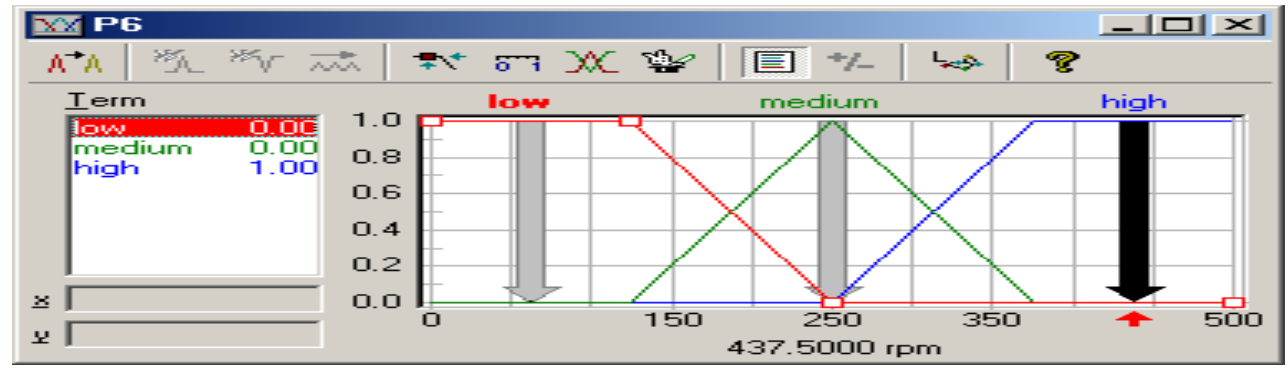

Figure 65: MSF for P6

The complete fuzzy logic control for Acid circulation and storage and out of step 3 is illustrated in figure 66 .

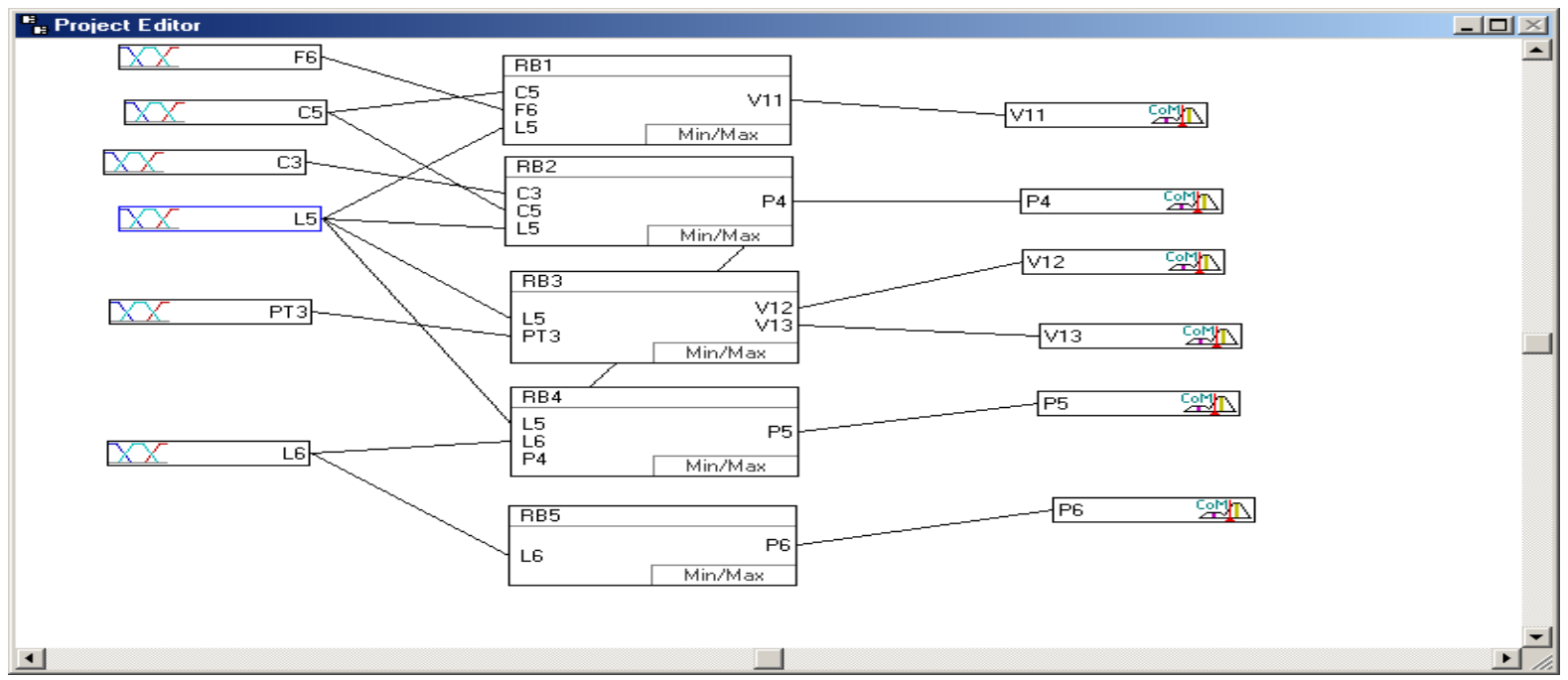

Figure 66: Fuzzy Control System for Step 3 stage 2 
Fuzzy logic based automation and control simulation of Sulfuric acid manufacturing process: A case

\section{Results}

The Fuzzy logic system made for step 1 is controlling the production of Sulfuric Dioxide gas with high temperature. Here the temperature and volume both are controlled. In addition if the limits exceeded then the production would stop and the same for the moister contamination would also be controlled. Different control strategies are fulfilled i.e control achieved for the sulfur melting, control achieved for pumping of sulfur and cleaning of sulfur and control achieved for air burner to producing sulfuric dioxide gas which is depicted by Time plot for HP in figure 67. In second control system, boiler and feed to the boiler of both water and sulfuric dioxide gas are controlled and on reaching the limit the feed of both would stop. But this also would increase the Air Burner's temperature and pressure which will be controlled by the first controller. The results are shown in figure 68 which shows that control is achieved for this particular process.

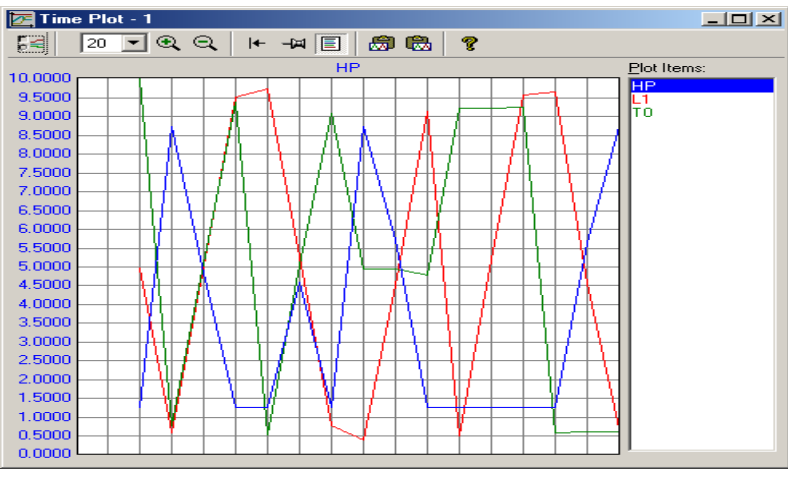

Figure 67: Time Plot for $\mathrm{HP}$

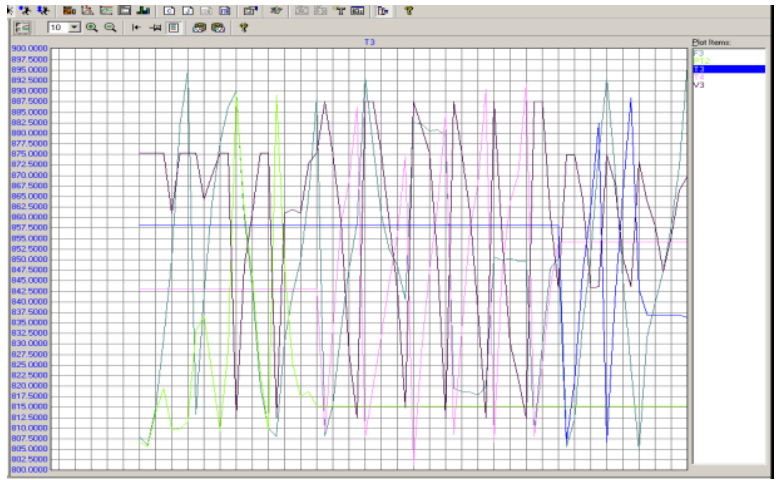

Figure 68: Time Plot for V3

The third control system controls feed to reactor and feed of coolant to heat exchanger respectively. Figure 69 shows time plot for the control achieved in the particular process. The time plot shows that control is achieved for this particular process. Fourth \& fifth control system controls feed of sulfuric trioxide to the absorber, vent of residue sulfuric trioxide to the environment, concentration control of both stages of absorber (by feeding sulfuric trioxide gas to first stage and by feeding low concentration sulfuric acid to the second stage this is what the pumping of sulfuric acid through the absorber) and storage of ready to dispatch sulfuric acid. The time plot in figure 70 shows that control achieved in.

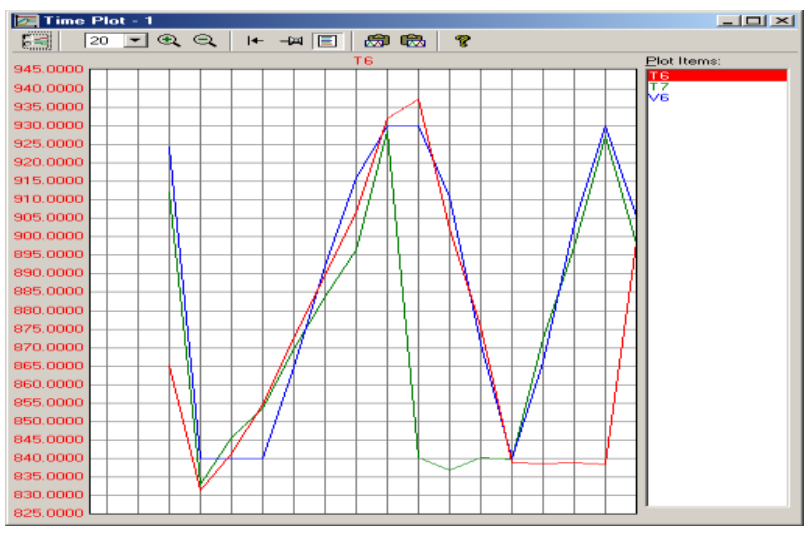

Figure 69: Time Plot for V6

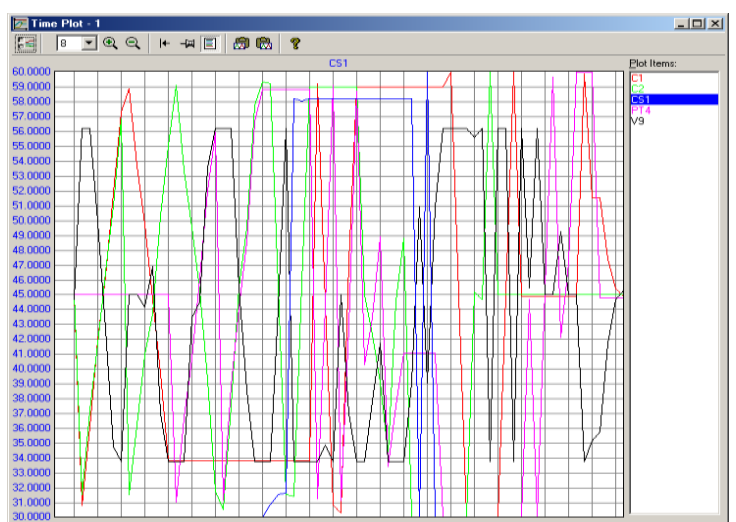

Figure 70 : Time Plot for V9

\section{Conclusions}

Five fuzzy control systems for the entire plant have been designed with loop identification, which is showing consistent results as elaborate in previous sections. If this work would be done by conventional method then it would require controller for each loop, thus fuzzy control system reduces both modeling for the processplant and detailed analysis for each loop for conventional control system. In addition expanded span with the help of linguistic variables give better approach for production with least errors; this shows reliability for this control phenomenon. The approach which circumvents the need for elaborating mathematical model of the complex chemical process and allows the use of qualitative information as linguistic rules is making knowledge base by integrating all individual fuzzy control loops and making a single control system. Mass Production of Sulfuric Acid from the higher capacity plant require to control number of melting tanks, air burners, west heat boilers with reactors and absorber. Neural fuzzy control may provide better solution for the control of large process plant. 


\section{References}

[1] Anna vasickaninova, Monika Bakosova, Dalibor Puna, Fuzzy Logic Control of a Chemical Reactor With Disturbances, 33rd international conference of SSCHE, May 22-26, 2006, Tatransk'e Matliare, Slovakia, vol. 132 pp. 1-8.

[2] Saeed Vaneshani and Hooshang Jazayeri-Rad, Nonlinear control of a chemical plant employing a combination of fuzzy logic and particle swarm optimization Techniques, International Journal Of Computer Applications (0975 - 8887) volume 33- no.9, November 2011, pp 6-13.

[3] E. R. Nucci; R. G. Silva; T. C. Gomes; R. C. Giordano; A. J. G. Cruz, a Fuzzy logic Algorithm for Identification of the Harvesting threshold during PGA production by Bacillus Megaterium, Brazilian journal of chemical engineering, vol.22 no.4, sao paulo Dec. 2005, pp 1-6.

[4] Vasickaninova, M. Bakosova, Cascade fuzzy logic control of a Chemical Reactor, 15th int. conference process control 2005, Strbske Pleso, Slovakia, pp1-5, vol.175 June 7-10, 2005

[5] M. santos, J.M. De La Cruz, S. Dormido, Influence of the information processing in fuzzy logic controllers, IPMU 96, Information Processing and Management of Uncertainty in Knowledge Based Systems, Granada, Spain, July 1-5, 1996.

[6] P.B. Osofisan, and O.J. Obafaiye, fuzzy logic modeling of the fluidized catalytic cracking unit of a petrochemical refinery, The Pacific Journal of Science and Technology, volume 8. No. 1. May 2007 (spring), pp59-68.

[7] Dinesh Singh Rana and Rajiv Sharma, "Fuzzy Logic Based Automation of Green House Environmental parameters for Agroindustries-A Simulation Approach" IJAER, Vol6 No.5(2011)pp662-666

[8] Rajvir Sharma, Dinesh Singh Rana etal, "A Fuzzy Logic based Automatic Control of Rotary Crane (A Simulation Approach)", Advance Materials Research, Vols.,403-408(2012)pp4659-4666

[9] D.F. Ahmed, S.K.H. Al-Dawery and H.A.O. Al-Anbari, On-Line Control of the Neutralization Process Based on Fuzzy Logic, Emirates journal for engineering research, vol. 12 (2), 89-97 (2007).

[10] Sourabh Dash, Raghunathan Rengaswamy, Venkat Venkatasubramanian, Fuzzy-logic Based trend Classification for Fault Diagnosis of Chemical Processes, Computers and Chemical Engineering Vol.27, pp. 347-/362, 2003 